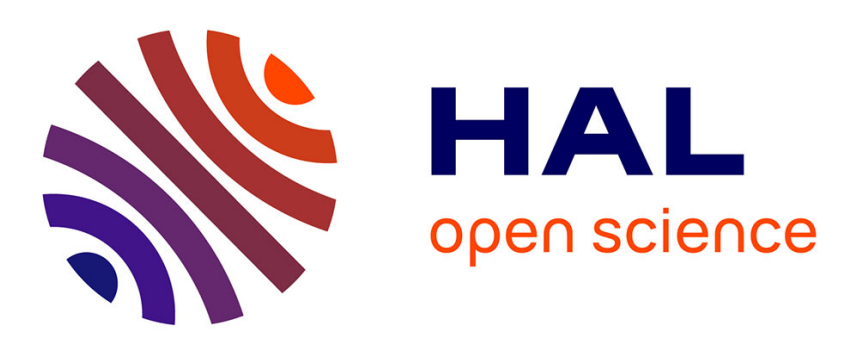

\title{
Mobility choices and climate change: Assessing the effects of social norms, emissions information and economic incentives
}

Charles Raux, Amandine Chevalier, Emmanuel Bougna, Denis Hilton

\section{To cite this version:}

Charles Raux, Amandine Chevalier, Emmanuel Bougna, Denis Hilton. Mobility choices and climate change: Assessing the effects of social norms, emissions information and economic incentives. Research in Transportation Economics, 2020, pp.101007. 10.1016/j.retrec.2020.101007 . halshs-03045959

\section{HAL Id: halshs-03045959 \\ https://shs.hal.science/halshs-03045959}

Submitted on 8 Dec 2020

HAL is a multi-disciplinary open access archive for the deposit and dissemination of scientific research documents, whether they are published or not. The documents may come from teaching and research institutions in France or abroad, or from public or private research centers.
L'archive ouverte pluridisciplinaire HAL, est destinée au dépôt et à la diffusion de documents scientifiques de niveau recherche, publiés ou non, émanant des établissements d'enseignement et de recherche français ou étrangers, des laboratoires publics ou privés. 


\title{
WORKING PAPERS DU LAET
}

\section{Mobility Choices and Climate Change: Assessing the Effects of Social Norms, Emissions Information and Economic Incentives}

\author{
Charles RAUX \\ Amandine CHEVALIER \\ Emmanuel BOUGNA \\ Denis HILTON
}

The potential of psychological and fiscal framing interventions in motivating environmentally responsible behavior is explored in a context of long distance leisure travel. A series of discrete choice experiments is conducted with 789 participants. Framing conditions like information on CO2 emissions, an injunctive and a descriptive norm, fiscal incentives such as a carbon tax, a bonus-malus and a personal carbon trading scheme are tested while controlling the usual travel price-duration tradeoff. Pricing (including internalization of social cost of $\mathrm{CO} 2$ through fiscal incentives) has the expected effect of reducing the choice of travelling and hence $\mathrm{CO} 2$ emissions. Providing information on $\mathrm{CO} 2$ emissions of each transport alternative significantly reduces preferences for the most emitting modes (air) and favors a less emitting mode (train). Framing the fiscal incentive as personal carbon trading adds a moderate incentive to the price effect in reducing air choice.

Keywords: transport, CO2 emissions; discrete choice experiments, psychological interventions, bonus-malus, personal carbon trading

\section{J.E.L. Classification: R480, R41, Q58}

Please cite this article as: Charles Raux, Amandine Chevalier, Emmanuel Bougna, Denis Hilton, 2020. Mobility choices and climate change: Assessing the effects of social norms, emissions information and economic incentives, Research in Transportation Economics,

https://doi.org/10.1016/j.retrec.2020.101007 (link to the published journal article). 


\section{NUMÉRO \\ 2020/04}

\section{Mobility Choices and Climate Change: Assessing the Effects of Social Norms, Emissions Information and Economic Incentives}

\section{Charles RAUX}

Univ Lyon, CNRS, LAET, F-69007, LYON, France

\section{Amandine CHEVALIER}

Univ Lyon, CNRS, LAET, F-69007, LYON, France

\section{Emmanuel BOUGNA}

Univ Lyon, CNRS, LAET, F-69007, LYON, France

\section{Denis HILTON}

Université Toulouse II, France

Novembre 2020

ISSN : 2741-8103

Laboratoire Aménagement Économie Transports

MSH Lyon St-Etienne

14, Avenue Berthelot

F-69363 Lyon Cedex 07 France pas dotés dền comité éditorial et les propos n⿳⺈⿴囗十⺝gagent que leur(s) auteur(s) avec ou sans review. auteur(s). 


\title{
Mobility Choices and Climate Change: Assessing the Effects of Social Norms, Emissions Information and Economic Incentives
}

\author{
Charles Raux ${ }^{\mathrm{a}^{*}}$, Amandine Chevalier $^{\mathrm{a}}$, Emmanuel Bougna $^{\mathrm{a}}$, Denis Hilton ${ }^{\mathrm{b}}$ \\ ${ }^{\mathrm{a}}$ Univ Lyon, CNRS, LAET, F-69007, Lyon, France \\ ${ }^{\mathrm{b}}$ University of Toulouse, France \\ * corresponding author: email: charles.raux@laet.ish-lyon.cnrs.fr , \\ address: LAET, MSH, 14 av. Berthelot, 69363 Lyon Cedex 07, France. \\ Phone: +33472726454 , Fax: +33472726448
}

\begin{abstract}
The potential of psychological and fiscal framing interventions in motivating environmentally responsible behavior is explored in a context of long distance leisure travel. A series of discrete choice experiments is conducted with 789 participants. Framing conditions like information on $\mathrm{CO}_{2}$ emissions, an injunctive and a descriptive norm, fiscal incentives such as a carbon tax, a bonus-malus and a personal carbon trading scheme are tested while controlling the usual travel price-duration tradeoff. Pricing (including internalization of social cost of $\mathrm{CO}_{2}$ through fiscal incentives) has the expected effect of reducing the choice of travelling and hence $\mathrm{CO}_{2}$ emissions. Providing information on $\mathrm{CO}_{2}$ emissions of each transport alternative significantly reduces preferences for the most emitting modes (air) and favors a less emitting mode (train). Framing the fiscal incentive as personal carbon trading adds a moderate incentive to the price effect in reducing air choice.
\end{abstract}

Keywords: transport; $\mathrm{CO}_{2}$ emissions; discrete choice experiments; psychological interventions; bonus-malus; personal carbon trading;

Declarations of interest: none

JEL: R480; R41; Q58

\section{ACKNOWLEDGEMENTS}

Funding: This work was supported by the French Research Agency ANR (Grant ANR-2010CEPL-009-02).

Comments from participants at various seminars including Toulouse "Economics of Energy and Climate Change" conference (2015) and Transportation Research Board 94th Annual Meeting in Washington (2015) are acknowledged, with a special mention to Henrik Andersson (Toulouse School of Economics). We also thank anonymous reviewers for their constructive remarks which helped us to improve the paper.

Please cite this article as: Charles Raux, Amandine Chevalier, Emmanuel Bougna, Denis Hilton, 2020. Mobility choices and climate change: Assessing the effects of social norms, emissions information and economic incentives, Research in Transportation Economics, https://doi.org/10.1016/j.retrec.2020.101007 (link to the published journal article). 


\section{INTRODUCTION}

According to the IEA (2018) transport accounted for one quarter of total world $\mathrm{CO}_{2}$ emissions from fuel combustion in 2016 and these are still continuously increasing. After repeated alerts by climate scientists urging sharp reduction of anthropogenic greenhouse gas emissions, the sense of urgency seems to be felt on the policy side in the Paris Agreement (2015) and more generally in public opinion. Regarding transport it is recognized that improvements undertaken in vehicle energy efficiency will not be sufficient in the coming decades and that behavioral changes are also needed, such as shifting from individual to public (or shared) transportation vehicles or to lower-emission modes per passenger-km or even reducing kilometers travelled.

When it comes to behavioral changes to reduce transport externalities, carbon taxes (CT) and vehicle taxes are advocated by the majority of economists as the most efficient instruments (Parry et al., 2007). According to the OECD (2018), which analyzed carbon pricing in 42 OECD and G20 countries, the average "pricing gap" (difference between the current benchmark value of 30 euros per ton of $\mathrm{CO}_{2}$ and the effective carbon rate including carbon tax and specific fuel tax) amounts to $21 \%$ for road transport and $58 \%$ for off-road transport. Moreover, this gap is narrowing at too slow a pace with respect to future benchmark values in 2030. A specific CT on fuel was introduced in France without public fanfare in 2014 in a period when fuel prices were rather low. In autumn 2018 its planned increase during a period of increasing fuel prices faced fierce popular opposition and was cancelled by the government. Indeed, public opinion can be very sensitive if not resistant to fuel tax increases.

Given the public sensitivity to economic incentives intended to reduce fuel consumption it is relevant to consider variants like carbon trading. Their roots in the economic literature can be found initially as a combination of economic incentive and quantity control, namely marketable or tradable permits (Baumol and Oates, 1988). "Domestic tradable quotas" covering transport and household energy were initially proposed by David Fleming in 1996. Raux and Marlot (2005) and Raux (2011) discuss pros and cons of downstream carbon trading schemes in transportation (also known as personal carbon trading, PCT). A variant of PCT includes also housing energy and was recently empirically explored by Wadud and Chintakayala (2019).

When compared with a CT potential supplementary outcomes are expected from PCT on psychological grounds rather than only economic ones (Fawcett, 2010). Another hybrid instrument named "bonus-malus" (similar in principle to feebates, see Greene et al, 2005) has been shown also to have such combined effects in some applications (see literature review below).

Other than the stated preference studies on PCT effectiveness referred to in the next section we do not know of any research which systematically examines the psychological effects of various framings of carbon schemes on behavior, and which isolates these aspects from their pure economic effects. In this paper, by "framing" we mean the ways of presenting a choice based initially on objective economic properties (here the trade-off between travel price and travel duration) that change the informational context (information on $\mathrm{CO}_{2}$ emissions), psychological aspects (social norms) or economic aspects (fiscal incentives).

The aim of this paper is to evaluate and compare the effectiveness of economic and psychological interventions in motivating environmentally responsible mobility behavior. We do so by the means of discrete choice experiments where we control for travel price and travel duration, while introducing in a controlled setting various framing conditions such as information on $\mathrm{CO}_{2}$ emissions, an injunctive social norm and a descriptive one, and fiscal framings such as a CT, a bonus-malus and a PCT scheme. 
The remainder of the paper is structured as follows. Section 2 provides a literature review and motivation for the research question. Section 3 describes the methodology of data production and analysis. Section 4 presents the results and section 5 discusses them.

\section{LITERATURE REVIEW AND RESEARCH QUESTIONS}

In their examination of instrument choice in environmental policy Goulder and Parry (2008) identify the main criteria at stake: they include economic efficiency (and costeffectiveness), distribution of costs and benefits (the equity issue), and political feasibility (also known as "acceptability" in the transport-related literature). They show that no single instrument is clearly superior per se, that trade-offs need to be made between equity and costeffectiveness, and that details in designing the instruments matter.

In his survey paper about the relevance of PCT, Starkey reviews the issue of equity (2012a) and concludes that, when compared with CT schemes, there is no advantage of PCT per se. Equity is recognized as of high importance for acceptability. Bristow et al (2010) apply stated preferences techniques to explore the acceptability of various PCT compared with CT schemes. They conclude that there is no preference of PCT over CT and that design of the instrument (e.g. initial permits allocation in the case of PCT or revenue use in the case of CT) has a critical influence on schemes acceptability.

When it comes to implementation costs PCT schemes are obviously more costly than a straightforward CT, despite their administrative and technological feasibility (see for instance Raux, 2011). Until now one can only speculate that due to the huge expansion of the Internet and smartphone-based technology transaction costs are rapidly decreasing.

When it comes to effectiveness one psychological effect expected with PCT might come from making carbon visible at the end-user level, with a carbon account delivering frequent feedback on travel behavior (i.e. "carbon budgeting", see Capstick and Lewis, 2009). Another effect could come from the implicit social norm concerning acceptable consumption associated with a personal allowance fixed within the frame of a public policy. However, current evidence regarding the compared effectiveness of CT and PCT is mixed (Starkey, $2012 b$ ). The few studies which actually implement stated preferences methodology to analyze effectiveness of PCT schemes arrive at the same mixed conclusion (Parag et al, 2011; Zanni et al, 2013; Raux et al, 2015), that is to say there is no evidence of greater effectiveness of PCT over CT.

Another instrument, the "bonus-malus", has been applied in France since 2008 to new car sales. "Bonus-malus" schemes are widely applied in vehicle insurance, where the premium paid by an individual customer varies according to his or her insurance claim history. In an environmental version (in France) the consumer-price of a new car is adjusted according to their $\mathrm{CO}_{2}$ emissions per $\mathrm{km}$. It is credited (bonus) when emissions are below some threshold (20 $\mathrm{g} \mathrm{CO}_{2}$ per $\mathrm{km}$ as of 2019 , basically electric vehicles) or taxed (malus) when above another threshold (116 $\mathrm{g} \mathrm{CO}_{2}$ per $\left.\mathrm{km}\right)$. This scheme showed unexpected success in encouraging purchases of small-engined cars when introduced in 2008. An econometric analysis (d'Haultfoeuille et al, 2011) shows that the consumer reaction cannot be attributed solely to price change and is more complex than expected. Hilton et al (2014) have tested a hypothetical bonus-malus scheme using travel options (air and train) on populations of students. They showed that the bonus-malus has both a price effect and a social norm effect but also a potential motivation "crowding out" effect ${ }^{1}$ (Frey, 1997; Frey and Stutzer, 2008) on travel intentions if the size of bonus-malus is large.

\footnotetext{
${ }^{1}$ Motivation crowding out means that promising monetary rewards for performing a pro-environmental behavior may undermine the individual's intrinsic motivation to do so.
} 
There is a long tradition in the research literature regarding the potential of behavioral interventions based on attitudes and norms in incentivizing proenvironmental behavior in general and in the transport sector in particular. In their review, Steg and Vlek (2009) identify three kinds of motivational factors. The first is based on weighing cost and benefits, with the theory of planned behavior (TPB - Azjen, 1991). The second is based on moral and normative concerns through the role of values (prosocial, altruistic, biospheric, and so on), environmental concern, moral obligations (e.g. norm-activation model; NAM - Schwartz, 1977), and the specific influence of social norms through the focus theory of normative conduct (Cialdini et al, 1991). The third kind of factor relates to affect, for instance in relation to the car ownership and use as instrumental, symbolic and affective. According to Steg and Vlek these three categories of factors proved to be predictive of at least some types of environmental behavior. Moral and normative factors seem more successful when behavioral change is of low cost for the individual.

Applications of this line of research in the transport field (for a recent review see Zavareh et al, 2020) include for instance: combining TPB and NAM to explain drivers' intentions to reduce or maintain their car use for commuting (Wall et al, 2007) or to understand attitudes and behavioral intentions regarding air travel (Davison et al, 2014); extending TPB with "personal norm" and "perceived mobility necessities" to explore the predictive capability of psychological factors on the ecological impact of daily mobility behavior (Hunecke et al, 2007); evidencing the influence of social descriptive norms on selfreported reduction of car use (Kormos et al, 2014); and combining TPB, NAM, theory of risk perception, motives and environmental self-identity to explain active travel behavior (Zavareh et al, 2020).

As pointed out by Steg and Vlek contextual factors should obviously be added to these motivational factors in order to explain behavior, in our case the pricing regime of various transport options. To our knowledge very few studies try to explore the interaction of this kind of economic context (pricing regime) with various motivational factors apart from Hilton et al (2014) who studied the normative effects of a bonus-malus scheme.

Our research goes further by combining an explicit treatment of the context through carbon pricing schemes with various moral and normative factors through the test of social norms (Cialdini et al, 1991). We will embed our treatments in a discrete choice framework (see methodology below) in order to rigorously control the effects of travel price and duration across various travel modes. These price and duration effects will be first measured in a control situation and then entered in combination through various treatments with the following factors.

First, personalized information is expected to influence behavior (Howarth et al, 2010) so we will test this hypothesis by introducing information on $\mathrm{CO}_{2}$ emissions of the trip on each travel option offered to the respondent. It is expected that providing this information will decrease the preference for high emitting travel options when compared with the control condition (without information). Then we will test the effect of two kinds of social norm, an injunctive and a descriptive social norm (Cialdini, 2003). Descriptive social norms characterize the perception of what most others typically do and injunctive social norms characterize the perception of what most others typically approve or disapprove. It is expected that each of these two norms might have a reinforcing effect added to the effect of information.

Second, we will test three ways of framing a fiscal incentive in pricing carbon. The first, carbon tax framing, is a conventional one. The aim of this test is to see if the motivation of an economic sanction on environmental grounds influences mode choice beyond the price effect. The second is a bonus-malus incentive wherein a malus increasing the initial price applies when the $\mathrm{CO}_{2}$ emissions exceed a given threshold and a bonus decreasing the initial 
price applies when the opposite. We hypothesize that it conveys a social norm linked to the threshold above which there happens to be a malus, which adds to the injunctive social norm described above. The expectation is that the norm attached to bonus-malus will add further behavioral change when compared to the injunctive norm.

Third, we will test a PCT scheme. In this scheme quotas (or carbon allowances) are initially allocated to each individual. Following his or her travel choices, the individual's carbon allowances account is debited in proportion of emissions of the chosen travel mode. If the account balance is in the red the individual must buy allowances as required (at a price fixed by a public agency), but if it is in credit he or she may sell his or her unused allowances to the public agency. From the point of view of financial expenditure this scheme is similar to the bonus-malus one. Like the bonus-malus the quota scheme conveys a social norm linked to the initial allocation of quotas. However the framing is somewhat different: in the case of bonus-malus the target (threshold) refers to each single trip while with the PCT scheme the target refers to an initial allocation expected to cover all travel emissions. The aim is here to test if this difference in framing yields a different behavior.

\section{METHODOLOGY}

Firstly the experimental setting is described, followed by the design of the discrete choice experiments and then sample description, to end by the modeling strategy and the utility specification.

\subsection{Experimental setting}

As the aim is to explore how the choice between travel modes is modified in various framing conditions while controlling the tradeoff between price and duration of travel, the field experiment addresses long distance leisure travel. Such travel choices are distinct from routine daily travel behavior and lead to specific decision at each occasion. Moreover, the quantity of $\mathrm{CO}_{2}$ emissions for each such travel decision is sufficiently large to yield significant values of decision parameters and to motivate the respondents to consider the trade-offs between the various alternatives conscientiously.

Participants were presented with a scenario in which they had decided to travel to a destination of their choice at about $1,000 \mathrm{~km}$ from their home location for a one weekvacation accompanied by a person of their choice. The one-week holiday duration aims at making ground transportation a relevant choice given the time necessary to travel this distance. Travelling with somebody else aims at making private car a plausible alternative given its cost. Participants had to choose between four different travel modes (air, car, bus, train) or renouncing travel altogether, in a series of choice situations with various combinations of travel price, duration and framing conditions.

As in a clinical trial a "control group" is established where only the price-duration tradeoff between travel modes has to be performed. For each of the subsequent experimental conditions another group of individuals is selected randomly and assigned to one and only one condition. This random selection allows making the assumption that the responses of any individual assigned to a given experimental condition can be compared with the responses of any individual assigned to another experimental condition. Moreover, because each group is assigned to one and only one condition the specific effect of the interventions introduced in each condition can be controlled.

The aim of the first experimental condition is to see if providing information on $\mathrm{CO}_{2}$ emissions encourages pro-environmental behavior when compared with the control condition. In the screens showing the duration and price tradeoff between alternative transportation modes, the amount of $\mathrm{CO}_{2}$ emissions associated with each travel mode is added. The quantity 
for a given mode is fixed regardless of travel duration (which is a simplification): $180 \mathrm{~kg}$ of $\mathrm{CO}_{2}$ for train; $720 \mathrm{~kg}$ for air; $124 \mathrm{~kg}$ for bus (round trip for two persons for these three transport modes); $408 \mathrm{~kg}$ for car (roundtrip for the vehicle) $)^{2}$.

In the second experimental condition an "injunctive norm" is added in order to assess the impact of such a psychological incentive. This injunctive norm was stated as follows: "The high level of greenhouse gas emissions in the atmosphere (such as $\mathrm{CO}_{2}$ ) can cause dangerous climate change for the planet. Climatologists are already seeing many consequences such as melting glaciers or ice field. According to scientists, to limit these effects it is necessary that the whole humans reduce their emissions by half'.

In the third experimental condition, a potential reinforcing effect by a "descriptive norm" is tested. The following sentence is added to the previous injunctive norm: " $60 \%$ of French people personally contribute through their daily actions to reducing their emissions". This statement is adapted from results of Eurobarometer relating to environment (2008) ${ }^{3}$.

The last three experimental conditions involve fiscal incentives added to the $\mathrm{CO}_{2}$ information and the injunctive norm. $\mathrm{CO}_{2}$ information and the injunctive norm are kept as necessary to make the introduction of fiscal incentives plausible. In the fourth experimental condition a carbon tax is applied starting from the first unit of fuel consumed and thus of $\mathrm{CO}_{2}$ emissions. The fifth experimental condition implements the bonus-malus scheme and the sixth and last experimental condition implements personal carbon trading (also named "quotas" in the following).

The control condition was run in June 2013 and was used to input parameters in the design of the subsequent experiments (see "Discrete choices design" below). The second experiment including experimental conditions 1, 2 and 3 was run in December 2013 and the third experiment including experimental conditions 4, 5 and 6 in June $2014^{4}$. Note that there are some cumulative aspects between framing conditions. In condition 2 an injunctive norm is added to $\mathrm{CO}_{2}$ information presented in experimental condition 1, while conditions 3 to 6 add a descriptive norm, a tax, a bonus-malus and quotas respectively to the $\mathrm{CO}_{2}$ emissions information and the injunctive norm presented in experimental condition 2.

\subsection{Discrete choices design}

Discrete choice experiments, as part of stated choice methods (Louviere et al, 2000; Hensher et al, 2015), involve various design issues which are linked, including the sample size, the number of choice situations submitted to the respondent and the number of attributes and levels including their ranges. We follow on this the methodology indicated by ChoiceMetrics (2014) and Rose and Bliemer (2005, 2013). The NGENE software (ChoiceMetrics) has been used to generate the designs.

\footnotetext{
${ }^{2}$ Various sources were consulted on the Internet in May 2013 when preparing the survey: for train: voyages-sncf.com; for air: French civil aviation eco-calculateur.dta.aviation-civile.gouv.fr; for bus: Eurolines calculateur de CO2 www.ecogreen.eurolines.fr; for car: ADEME, 2008.

${ }^{3}$ This is a "reasonable" statement based on the following results: in answering to the question "Did you perform one of the following actions for environmental reasons during the last month?" $82 \%$ of French people stated that they sorted their waste, 53\% reduced their energy consumption, 58\% reduced their water consumption, and so on.

${ }^{4}$ This spreading of experiments over a one year period was mainly due to the need to use results of the first experiment as input to the design of the subsequent experiments and administrative delays in ordering the web survey. There was no significant change in oil price (including high domestic taxes in France) in the survey period from June 2103 to June 2014 (oil price started to decrease significantly after summer 2014). A carbon tax was introduced by the government in April 2014 but with a different name avoiding the word "tax" ("contribution climat énergie"). The initial level was low ( $7 €$ per $\mathrm{CO} 2$ ton, i.e. approximately 2 cents euro per liter of petrol, which was not visible at the pump compared to price fluctuations). At this time this introduction resulted in little reaction from the public.
} 
Regarding the levels of duration and price attributes a compromise was made between presenting realistic values and the statistical need for a large range of levels. An informal survey of travel prices proposed by travel agencies on the Internet led us to propose four price levels for a round trip for two people, that is 400, 500, 600 and 700 Euros, applicable to the four modes. Regarding one-way trip duration different levels were applied depending on the mode: air: 3h (direct flight), 5h, 10h (with connections); car and bus: 10h, 17h; train: $5 \mathrm{~h}$ (high speed train), 10h, $17 \mathrm{~h}$.

The control condition was conducted on an orthogonal design in order to find prior values for the duration and price parameters to be used in the design of subsequent experiments (see Rose and Bliemer, 2005). The sample size target was 300 individuals - in order to get accurate priors - who were each presented 6 choice situations. S-efficient designs were elaborated for each of the six subsequent experiments, with a sample size target of $\mathrm{N}=100$ individuals in each condition, each individual being presented with 6 choice situations.

In the carbon tax scheme the tax level was given three values: 3, 5 and 10 Euro-cents per $\mathrm{kg}$ of $\mathrm{CO}_{2}$. This corresponds to respectively 30, 50 and 100 Euros per ton of $\mathrm{CO}_{2}$. Values of 30 and 100 Euros are listed in a French law dating from $2015^{5}$ respectively for present time and for 2030 in order to give the right economic signal for optimal $\mathrm{CO}_{2}$ reductions. Notice that, as said above, the quantity of $\mathrm{CO}_{2}$ emitted by each travel mode is fixed. Thus the gross tax value varied between $4 €$ and $72 €$.

These three same levels of unit tax are used in the bonus-malus scheme (unit bonusmalus per $\mathrm{kg}$ of $\mathrm{CO}_{2}$ ) and the quota scheme (unit price of $\mathrm{kg}$ of $\mathrm{CO}_{2}$ to buy or sell). Moreover, in the bonus-malus and quota schemes an additional attribute was respectively the threshold and the amount of quotas available. This attribute was randomly given three levels: 150, 300 or $500 \mathrm{~kg}$ of $\mathrm{CO}_{2}$. These levels were chosen in order to have varying situations of emissions over or under the threshold according to the various travel modes. Note that with this setting air emissions are always over the threshold (or amount of quotas) while bus emissions are always under. Overall, the design of the experimental conditions involved three attributes (travel duration, price, tax) in the tax scheme and four attributes (adding the threshold) in the bonus-malus and quota schemes. Thus the tax/reward value varied between $-38 €$ (bonus or quotas to sell) and $57 €$ (malus or quotas to buy).

The attributes and levels are recapitulated in Table 1

\begin{tabular}{ll}
\hline Attributes & Levels \\
\hline Duration & Air: $3 \mathrm{~h}, 5 \mathrm{~h}, 10 \mathrm{~h}$ \\
& Car, Bus: $10 \mathrm{~h}, 17 \mathrm{~h}$ \\
& Train: $5 \mathrm{~h}, 10 \mathrm{~h}, 17 \mathrm{~h}$ \\
Price & $400,500,600,700 €$ \\
Tax, Bonus-malus, Quotas & $3,5,10 € \mathrm{cents}$ per $\mathrm{kg} \mathrm{CO}_{2}$ \\
Threshold (Bonus-malus, Quotas) & $150,300,500 \mathrm{~kg} \mathrm{CO}{ }_{2}$ \\
\hline
\end{tabular}

\section{Table 1: Attributes and levels in the experimental design}

Screen examples of one choice exercise for the control and each of the six experimental conditions are given in Appendix A. As it may be seen some alternatives may dominate others when taking only travel price and duration into account (e.g. air compared with bus and train). However, the respondent may trade-off these attributes against $\mathrm{CO}_{2}$ emitted from his or her travel choice since the airplane emits much more than the bus or train. Note also that the order of presentation of mode alternatives (columns) was rotated along the 6 choice situations.

${ }^{5}$ Loi n ${ }^{\circ}$ 2015-992 du 17 août 2015 relative à la transition énergétique pour la croissance verte (https://www.legifrance.gouv.fr) 


\subsection{Sample description}

The seven conditions were each conducted via an Internet panel provider ${ }^{6}$ on seven different samples, totaling 900 participants distributed in eight French urban areas (Paris, Lyon, Marseille, Toulouse, Lille, Bordeaux, Nice, Nantes). These eight areas were selected as they host the main French airports (in passenger traffic) connected to the world airline network. Each of the seven samples was selected as representative of the French population living in these urban areas according to the quota method (gender $\mathrm{x}$ age, household job status, urban area) with individuals aged from 25 to 70 .

Among the initial 900 respondents who participated in one of the seven conditions, 16 persons chose systematically the "renouncing travel" option, which represents only $1.8 \%$ of the sample. This low percentage is an indirect indication of the quality of the survey protocol and we removed these respondents from the analysis. Moreover, the requirement that an individual of the panel participates to one and only one of the seven conditions was checked. Eight individuals of the Internet panel were found to have participated in two conditions and they were removed, which yields 876 individuals in all.

Furthermore, as our stated choice survey aims at making respondents trade off between travel price, duration and $\mathrm{CO}_{2}$ emissions, and hence obtain accurate estimates of this trade-off, checking and cleaning of data is needed. Respondents may be non-trading (i.e., always choose the same alternative), have a lexicographic choice strategy (i.e. always choose an alternative on the basis of a subset of attributes) or behave inconsistently when compared to the axioms of rational choice behavior (for a discussion of these issues see Hess et al, 2010). In our sample 125 people (14\%) always choose the same alternative (no change): among them $53 \%$ always choose air, $24 \%$ car, $21 \%$ train and $2 \%$ bus. One of the explanations of these choices may be that respondents wanted to terminate quickly the survey by always choosing the same alternative. However the order of presentation of alternatives was rotated at each screen change so that the systematic choice of a given alternative involved scrolling the entire screen in order to find the right option. We favor the other explanation that is the respondents express an extreme preference for the chosen mode and so we keep these respondents. One drawback is a probable overestimation of preference for speed given the preference for air which is generally (but not always) the fastest mode (high speed train may be faster in some choice situations). Regarding the lexicographic strategy 234 respondents (27\%) always chose the fastest alternative, expressing here again a strong preference for speed, but only $32 \%$ of them were in the no change category. 32 respondents (4\%) always chose the cheapest alternative. Overall these two kinds of behavior may be interpreted as rational ones, expressing a strong preference for time savings or for cost savings. Finally, regarding inconsistent behavior, we detect 87 respondents (10\% of the sample) who in any choice situation happened to choose an alternative while there was another faster and less expensive one (and with less $\mathrm{CO}_{2}$ emissions in the case of conditions 1 to 6). This last category of respondents was eliminated from the study sample, giving 789 respondents for analysis.

The experimental protocol with the sample size in each condition is recapped in Table 2.

${ }^{6}$ The panel access provider was one of the main French polling and market research institute. This permanent panel offered all the guarantees of quality. 
Table 2: Phasing of experiments

\begin{tabular}{|c|c|c|c|c|c|}
\hline $\begin{array}{l}\text { Experimental } \\
\text { conditions }\end{array}$ & Description & Abbreviation & When & $\mathrm{N}$ respondents & $\mathrm{N}$ selected \\
\hline Control & Price and duration tradeoff & & June 2013 & 300 & 229 \\
\hline 1 & $\begin{array}{l}\text { Price and duration tradeoff } \\
+\mathrm{CO}_{2} \text { emissions information }\end{array}$ & $\mathrm{CO}_{2}$ & December 2013 & 100 & 97 \\
\hline 2 & $\begin{array}{l}\text { Price and duration tradeoff } \\
+\mathrm{CO}_{2} \text { emissions information }+ \\
\text { injunctive norm }\end{array}$ & $\mathrm{CO}_{2}+\mathrm{IN}$ & December 2013 & 100 & 93 \\
\hline 3 & $\begin{array}{l}\text { Price and duration tradeoff } \\
+\mathrm{CO}_{2} \text { emissions information }+ \\
\text { injunctive norm }+ \text { descriptive norm }\end{array}$ & $\mathrm{CO}_{2}+\mathrm{IN}+\mathrm{DN}$ & December 2013 & 100 & 97 \\
\hline 4 & $\begin{array}{l}\text { Price and duration tradeoff } \\
+\mathrm{CO}_{2} \text { emissions information }+ \\
\text { injunctive norm }+ \text { tax }\end{array}$ & $\mathrm{CO}_{2}+\mathrm{IN}+\operatorname{tax}$ & June 2014 & 100 & 94 \\
\hline 5 & $\begin{array}{l}\text { Price and duration tradeoff } \\
+\mathrm{CO}_{2} \text { emissions information + } \\
\text { injunctive norm + bonus/malus }\end{array}$ & $\mathrm{CO}_{2}+\mathrm{IN}+\mathrm{BM}$ & June 2014 & 100 & 94 \\
\hline \multirow[t]{2}{*}{6} & $\begin{array}{l}\text { Price and duration tradeoff } \\
+\mathrm{CO}_{2} \text { emissions information + } \\
\text { injunctive norm + quotas }\end{array}$ & $\mathrm{CO}_{2}+\mathrm{IN}+$ quotas & June 2014 & 100 & 85 \\
\hline & & & Total & 900 & 789 \\
\hline
\end{tabular}

Table 11 (in Appendix B) shows socio-demographic attributes of the sample in each of the seven conditions. Regarding gender, age, job status household and urban area, the constitution of the final sample reflects of course the initial quota target. For instance, $57 \%$ of the French population of the eight urban areas live in the Ile-de-France (Paris) region, that is to say about 12 million inhabitants. Moreover, in our sample $72 \%$ of the individuals are working or seeking a job and $20 \%$ are retired.

Regarding income, a question regarding the overall income (in 16 classes) of the household was asked at the end of the series of exercises. The non-response rate was $1 \%$. The median income stated by the respondents is 30,000 euros per year, in line with the French population median income (net of income tax) which was 29,540 euros in 2013 (INSEE, 2016). Since the subsequent analysis is performed at the individual level, we computed a personal income based on the median of household income class and the composition of the household (number of "consumption units"), divided into 4 classes (less than 1200 euros per month, between 1200 and 1800, between 1800 and 2600, more than 2600).

\subsection{Modeling strategy}

We thus seek to estimate the modal choice where the individual $i$ compares the different levels of utility associated with various travel alternatives and chooses the one that maximizes his utility.

For the individual $i$, the utility of the alternative $j$ is (assuming a linear in parameters specification):

$$
U_{i j}=\beta_{j} X_{i j}+\varepsilon_{i j}=V_{i j}+\varepsilon_{i j}
$$

where $X_{i j}$ is a vector of attributes including one for the alternative specific constant, attributes of travel mode alternative $j$ (such as time or cost) for the individual $i$, and individual characteristics (such as gender, age or income and the different framing conditions) which do not vary with alternatives, 
$\beta_{j}$ a vector of parameters which may be alternative specific regarding the mode attributes and are generally alternative specific for individual characteristics (as only differences in utility of alternatives matter) and $\varepsilon_{i j}$ a random error term.

With the assumption that $\varepsilon_{i j}$ is identically and independently extreme value distributed (iid), we obtain the well-known multinomial conditional logit model (McFadden, 1973) with the probability that the individual $i$ chooses the alternative $j$ among the set of alternatives $k$ expressed as

$$
P_{i j}=\operatorname{Prob}\left(V_{i j}+\varepsilon_{i j}>V_{i k}+\varepsilon_{i k} \forall k \neq j\right)=\frac{\exp \left(V_{i j}\right)}{\sum_{k} \exp \left(V_{i k}\right)}
$$

However, the multinomial logit model suffers from three limitations which prevent its direct application in our study (we follow the discussion on specification for discrete choice experiments by Lancsar et al, 2017):

- The first limitation is the well known independence of irrelevant alternatives axiom (iia): in our case for instance a change in the preference for air will probably have a different impact on the choice of other travel modes or renouncing travel, thus invalidating the iia axiom.

- The second limitation is that since each respondent is performing repeated choice exercises, unobserved preferences may induce correlation across the choice exercises, which invalidates the iid errors assumption and implies taking account of the data panel structure.

- The third limitation is the assumption of constant attribute weight across individuals: given our sample selection it is wise to consider the possibility of different weights across individuals (preference heterogeneity).

This is why we implement the random parameters logit model (or mixed logit, see Hensher and Greene, 2003) which allows to address these three limitations. In equation (1) the $\beta_{j}$ become individual specific parameters $\beta_{i j}$. They are distributed randomly across individuals with fixed means i.e. $\beta_{i j}=\beta_{j}+\sigma_{j} v_{i j}$ where $v_{i j}$ is the individual specific heterogeneity.

Following Train (2009) we can express the mixed logit probabilities are the integrals of standard logit probabilities over a density of parameters.

$$
P_{i j}=\int L_{i j}(\beta) f(\beta) d \beta
$$

where $f(\beta)$ is a density function and $L_{i j}(\beta)$ the logit probability evaluated at $\beta$

$$
L_{i j}(\beta)=\frac{\exp \left(V_{i j}(\beta)\right)}{\sum_{k} \exp \left(V_{i k}(\beta)\right)}
$$

This specification is extended to take account of $T$ repeated choices by each sample individual. The utility for individual $i$ in choice situation $t$ becomes

and

$$
U_{i j t}=\beta_{i j} X_{i j t}+\varepsilon_{i j t}
$$

$$
P_{i j}=\int \prod_{t=1}^{T} \frac{\exp \left(\beta_{i j} X_{i j}\right)}{\sum_{k} \exp \left(\beta_{i k} X_{i k}\right)} f(\beta) d \beta
$$

However, as pointed by Hensher and Greene (2003) one essential issue is the choice of the distribution of the random parameters, an assumption to be made by the analyst.

Another good candidate is the latent class model (Greene and Hensher, 2003; Hess et al, 2009; Hess, 2014). In a latent class logit model the respondent $i$ belongs to a class $c$ with probability $\pi_{i c}$. In each class the choice probability is modeled as a logit and within the class 
the individual choices from one situation to the next are assumed to be independent. The probability for respondent $i$ choosing the alternative $j$ is

$$
P_{i j}=\sum_{c=1}^{C} \pi_{i c} \prod_{t=1}^{T} P_{i}\left(j t \mid \beta_{c}\right)
$$

where $P_{i}\left(j t \mid \beta_{c}\right)$ is the probability of respondent $i$ choosing alternative $j$ in choice situation $t$ conditional on respondent $i$ belonging to class $c$.

The main advantage over the random parameter logit model is that no assumption is required regarding the distribution of the random parameters. However the number of classes must be chosen, which is another assumption. Moreover, the class specific probabilities may be estimated as a set of fixed constants or linked (generally through another logit model) to individual characteristics.

In our various trials to estimate latent class models, the optimal number of classes was found to be equal to two. Introducing socioeconomic characteristics to explain class membership was inconclusive since none were significant.

The various models have been estimated with NLOGIT 6 (Econometric Software Inc.)

\subsection{Utility specification}

Various specifications regarding the generic or mode-specific characteristic of price and duration coefficients have been tested. The specification where travel time is mode specific but not travel cost performs statistically better than the others (both attributes generic or mode-specific). Thus we retain a specification when duration is mode-specific (i.e. duration of travel is valued differently according to travel mode).

The framing conditions are designated as "effects" in the equations below. Framing conditions apply at the individual level and like other individual characteristics (age, gender, etc.) they do not vary across travel mode alternatives. In discrete choice models estimating the differences in utility levels attached to each alternative, the only way to measure their influence is to make them alternative specific. Thus their coefficients are considered as modespecific, i.e. each framing condition influence varies with travel mode.

Since the various framing conditions involve some cumulative effect (e.g. condition 5 adds bonus-malus to condition $2, \mathrm{CO}_{2}$ information and injunctive norm), the differential effect of each framing condition is analyzed. That is condition $1\left(\mathrm{CO}_{2}\right.$ information) is compared with the control condition (no $\mathrm{CO}_{2}$ information), condition $2\left(\mathrm{CO}_{2}+\mathrm{IN}\right)$ with condition 1 $\left(\mathrm{CO}_{2}\right)$ and then conditions 3, 4, 5, 6 with condition 2. Overall this yields six pairwise comparisons. In order to assess the differential effect of condition $m$ with regard to condition $k$, we estimate the models on a sample aggregating the two subsamples which are faced with respectively condition $k$ and condition $m$. The equations below show how the travel modes utilities are specified.

$$
\begin{aligned}
& U_{\text {mode }}=\text { asc }_{\text {mode }}+d_{\text {mode }} \text { duration }+ \text { p.price }+e_{\text {mode }, m} \text { effect } \\
& U_{\text {none }}=0
\end{aligned}
$$

where mode is air, car, bus or train; asc is the alternative specific constant; effect is the effect being tested (dummy $=1$ for effect $=m$ else zero); $d, p$ and $e$ are parameters.

In the utility specification above the renouncing travel alternative ("none") is the reference. Thus each travel mode individual utility is measured as a difference towards utility of renouncing travel.

Note that with this specification we control the effect of price (including its fiscal component) separately from the "pure" framing conditions captured through the effect $t_{m}$ coefficients. 
For instance, in order to assess the differential framing effect of condition $1\left(\mathrm{CO}_{2}\right.$ information) with regard to the control condition, we estimate the models on a sample aggregating the two subsamples which are faced with respectively the control condition and the first experimental condition $\left(\mathrm{CO}_{2}\right)$. The utility specification is then

$U_{\text {mode }}=a s c_{\text {mode }}+d_{\text {mode }}$ duration + p.price $+e_{\text {mode, } \mathrm{CO} 2}$ effect $\mathrm{CO} 2_{2}$

The same applies when comparing condition 2 (CO2 information + Injunctive Norm) to condition 1 ( $\mathrm{CO} 2$ information) with the sample aggregating the two samples facing these two conditions and the utility specification below

$U_{\text {mode }}=a s c_{\text {mode }}+d_{\text {mode }}$ duration + p.price $+e_{\text {mode }, \mathrm{CO} 2+\mathrm{IN}}$ effect $\mathrm{CO} 2+\mathrm{IN}_{\mathrm{N}}$

For each comparison of two conditions we estimate three kinds of models: a multinomial logit (MNL), a random parameter logit (RPL) and a latent class (LC) model on the relevant sample.

Following Lancsar et al (2017) the specification of our models includes random alternative specific constants (ASC) with correlation in order to take account of the panel structure and the iia issue. Estimations of specifications with full random attribute parameters (duration with normal distribution and price with lognormal distribution) in order to take account of the individual preference heterogeneity have shown that standard deviations of these distributions were not significantly different from zero. Thus we keep duration and price parameters as not random. Other parameters (ASC and effects) are specified as random with a normal distribution.

Moreover, introducing socioeconomic characteristics in the models, i.e. gender, age in four classes, residence zone in two classes - Ile-de-France vs others -, status and personal income in four classes, does not improve significantly the models. Thus we did not include these individual characteristics in the estimations.

\subsection{Simulation of "what if" scenarios}

Furthermore, when the differential framing effect is shown significant at least for one travel mode (in the RPL model or in any class of the LC model) we also simulate "what if" scenarios in order to assess how any framing condition may change travel mode choice when compared with its reference condition. The change in modal choices is computed by comparing a scenario where only the reference condition (e.g. control) would apply entirely to the two subsamples to a scenario where framing condition (e.g. $\mathrm{CO}_{2}$ information) would apply entirely to the same sample. The same simulation procedure is applied to comparing condition 1 and 2, then condition 2 and 3,2 and 4 and so on (this procedure uses the simulation capability of Nlogit). The changes in percent share come from simulations computing the predicted choice probability times the number of observations in the simulated sample.

\section{RESULTS}

We first give the overview of responses and discuss their realism. Then we present detailed results for each differential effect of framing.

\subsection{Overview of responses}

Table 3 below gives an overview of choices made by the respondents in the 4734 choice situations ( $789 \times 6$ choice situations) across the seven experimental groups (control +6 
conditions). Overall, air is by far the mode chosen most often but its share varies significantly between the conditions. The second mode chosen is train and then car, followed by bus but with significant variations. The renouncing travel ("none") is the least chosen option. We analyze these variations in further detail in the next section.

Table 3: Distribution of choices among alternatives

\begin{tabular}{|c|c|c|c|c|c|c|c|c|}
\hline & air & car & bus & train & none & total & N choice & situations \\
\hline Control & $60 \%$ & $9 \%$ & $3 \%$ & $23 \%$ & $6 \%$ & $100 \%$ & & 1374 \\
\hline $\mathrm{CO}_{2}$ & $43 \%$ & $10 \%$ & $12 \%$ & $29 \%$ & $7 \%$ & $100 \%$ & & 582 \\
\hline $\mathrm{CO}_{2}+\mathrm{IN}+\mathrm{DN}$ & $46 \%$ & $13 \%$ & $9 \%$ & $29 \%$ & $3 \%$ & $100 \%$ & & 582 \\
\hline $\mathrm{CO}_{2}+\mathrm{IN}+\operatorname{tax}$ & $43 \%$ & $22 \%$ & $5 \%$ & $24 \%$ & $6 \%$ & $100 \%$ & & 564 \\
\hline $\mathrm{CO}_{2}+\mathrm{IN}+\mathrm{BM}$ & $35 \%$ & $20 \%$ & $4 \%$ & $37 \%$ & $3 \%$ & $100 \%$ & & 564 \\
\hline
\end{tabular}

A first issue which arises with this hypothetical framework is whether the respondents are stating "realistic" behavior. One basic way to evaluate the realism of responses is to estimate the value of travel time savings (VTTS) implied by their responses and assess them with empirical evidence available.

Random parameter logit models are estimated for each of the seven experimental groups (with the alternative specific constants specified as random and correlated, see above; details of the seven models are given in Appendix C). Then VTTS are computed as the ratio of the duration and cost coefficients. These VTTS per group and per mode are shown (in euro per hour) in Table 4 along with their $95 \%$ confidence intervals. We can notice that within each of the seven groups, when considering confidence intervals, VTTS per mode overlap.

Table 4: Values of travel time savings in each experimental group with $95 \%$ confidence interval (in euro per hour)

\begin{tabular}{ccccc}
\hline & air & car & bus & train \\
& & & & \\
Control & 39 & 31 & 25 & 38 \\
& {$[34,44]$} & {$[23,39]$} & {$[11,39]$} & {$[33,43]$} \\
$\mathrm{CO}_{2}$ & 51 & 47 & 69 & 51 \\
& {$[40,62]$} & {$[31,62]$} & {$[34,104]$} & {$[42,60]$} \\
$\mathrm{CO}_{2}+\mathrm{IN}$ & 48 & 31 & 61 & 50 \\
& {$[36,59]$} & {$[19,44]$} & {$[26,96]$} & {$[40,60]$} \\
$\mathrm{CO}_{2}+\mathrm{IN}+\mathrm{DN}$ & 45 & 43 & 65 & 47 \\
& {$[34,56]$} & {$[30,55]$} & {$[24,106]$} & {$[39,56]$} \\
$\mathrm{CO}_{2}+\mathrm{IN}+$ tax & 20 & 36 & 16 & 31 \\
& {$[9,32]$} & {$[24,48]$} & {$[-1,33]$} & {$[23,39]$} \\
$\mathrm{CO}_{2}+\mathrm{IN}+\mathrm{BM}$ & 31 & 29 & 33 & 35 \\
& {$[19,42]$} & {$[17,40]$} & {$[13,53]$} & {$[27,43]$} \\
$\mathrm{CO}_{2}+\mathrm{IN}+$ quotas & 31 & 10 & 27 & 25 \\
\hline
\end{tabular}

A first assessment can be made with the control group where there is no intervention such as $\mathrm{CO}_{2}$ information or social norms or fiscal incentives, thus reflecting actual framing conditions at the time of the survey.

French revealed preferences values for leisure travel (over $400 \mathrm{~km}$ ) reported by CGSP (2013) are $52 €$ per hour for air, $12 €$ for car, $10 €$ for bus, $22 €$ for train (values in euros 
2010). We notice that the VTTS in the control condition are lower than the revealed preferences ones for air and much higher for other travel modes. The specific high value of travel time for train $(38 €)$ can be explained by the fact that in our experiment we propose high speed train with travel durations comparable to those for air.

Differences in VTTS per travel mode for leisure trips can have various sources (see for instance Mackie et al, 2003). One reason is that faster modes (e.g. air or high speed train, generally more expensive) are chosen by people with higher average value of time (and also with higher income on average). Another reason is that time spent on a given mode may be perceived as less pleasant or comfortable (e.g. for safety reasons whether on air or road), or lengthy on a slower mode (e.g. by car or bus): hence VTTS on this mode would be larger. Given these opposite influences the resulting effect on VTTS per mode is in theory not straightforward.

The discrepancies of stated VTTS in the control condition with revealed ones can be attributed to several reasons. First, in our experimental design the supply differs from the actual one: travel cost varies randomly across the four modes while different levels are applied to duration depending on the mode (e.g. from $3 \mathrm{~h}$ to $10 \mathrm{~h}$ for air, $10 \mathrm{~h}$ and $17 \mathrm{~h}$ for car and bus). Second, the distance considered in the experiment $(1000 \mathrm{~km})$, clearly above the 400 $\mathrm{km}$ threshold in the empirical values reported, can reinforce the lengthy perception of time on slower mode and hence their VTTS. However, despite overlapping of confidence intervals, the overall ranking of modes VTTS is respected: air and train first then car and bus.

When it comes to the three first experimental conditions which involve interventions like $\mathrm{CO}_{2}$ information and social norms, a sharp increase of VTTS can be observed for each mode when compared with control (but it is not strictly significant if we consider confidence intervals). With these interventions VTTS stem now from a willingness to accept (WTA) perspective: respondents accept to spend more time in general or on slower modes (e.g. buses) in order to emit less $\mathrm{CO}_{2}$ (notice also there was also an injunction to travel since the wording was "Imagine you have decided to go on holiday..."). This increase in VTTS is also observed in another context, for drivers who accept money to get carpool passengers onboard (Monchambert, 2020). The higher values of WTA when compared to willingness to pay (WTP) ones, as conventionally measured with the previously quoted revealed VTTS, is well documented both on theoretical and empirical grounds on a wide variety of goods (see Horowitz and McConnell, 2002). Moreover, regarding the measure of value of time de Borger and Fosgerau (2008) found a gap of four between WTP and WTA. Thus the increases in VTTS observed in our survey are in line with the literature.

The three next experimental conditions add fiscal framings and financial incentives to the combination of $\mathrm{CO}_{2}$ information and injunctive norm. Overall, for each mode VTTS are similar in magnitude across the fiscal conditions when compared to control. An explanation of this similarity of VTTS can be attributed to the fact that with internalization of the social cost of $\mathrm{CO}_{2}$ the experiment comes back to a WTP study where respondents may tradeoff travel price and duration in the same way as in the control condition.

Overall the consistency of the responses across the various conditions and their assessment in view of the literature make us reasonably confident about the quality of the survey. We then explore in further detail the influences of the various covariates.

\subsection{Detailed results}

In what follows we use the abbreviations of experimental conditions listed in Table 2: " $\mathrm{CO}_{2}$ " as an abbreviation for $\mathrm{CO}_{2}$ information, "IN" for the injuctive norm, "DN" for the descriptive norm, "Tax" for the carbon tax, "BM" for the bonus-malus scheme and "Quotas" for the quotas scheme. 
The following tables (Table 5 to Table 10) show the estimations of the three models (multinomial logit - MNL, random parameters logit - RPL and latent class logit - LC) for the pairwise comparison of conditions. We apply the threshold of $95 \%$ for the confidence level (i.e. $\mathrm{t}=1.96$ ). For each pair the overall quality of fit of the MNL (see "Pseudo R2 adj.") is substantially lower than the two other models, so we do not comment this model. In each case the overall quality of fit is the best for the RPL model followed by the LC model. The RPL estimations show that the standard deviations of distributions are significant for all random parameters (alternative specific constants and various conditions) except for the coefficient "quotas-bus" (see Table 10, $\mathrm{t}=1.9$ ). In each case the LC model provides two latent classes with significant (non-zero) probabilities. Moreover, in some cases coefficients had to be fixed in order to get consistent estimates in some classes (this is the case for " $\mathrm{CO}_{2}$-air" in Table 5, for "BM-bus" in Table 9 and for "quotas-bus" in Table 10).

While the heterogeneity of respondents regarding the framing effects is validated first with the RPL models, this heterogeneity is made even more salient in the LC models. For instance in Table 6 it can be seen that in class 1 the "IN" framing effect is significantly positive both for car and bus choice while the sign is the opposite in class 2 . The resulting effect shown by the simulation depends on the class membership probabilities. It is positive for car choice and slightly negative for bus choice. Opposite signs are also seen in Table 7 ("DN"-bus and train) and in Table 10 ("quotas"-air and train).

We now focus on detailed comparisons. Table 5 (" $\mathrm{CO}_{2}$ information" condition versus control) shows that in the RPL model the $\mathrm{CO}_{2}$ effect is significant and negative only for air choice. In the LC model class 1 the $\mathrm{CO}_{2}$ effect is significantly negative on air and train choice. In class 2 the $\mathrm{CO}_{2}$ effect is also significantly negative on air choice but significantly positive on bus and train choice. The simulations performed both with the RPL and the LC models show that with $\mathrm{CO}_{2}$ information air choice would be lower $(-17 \%$ and $-16 \%$ respectively) and train choice would be higher $(+13 \%$ and $+11 \%$ respectively). Notice that there are similarity and difference with what is observed in the sample (see Table 3 ) where air share is lower $(-17 \%)$ while train share $(+6 \%$ only) and bus share are higher $(+9 \%)$.

Table 6 ("CO $2+\mathrm{IN}$ " versus " $\mathrm{CO}_{2}$ information") shows that in the RPL model the "IN" effect is significant and positive for bus choice (and positive also for car choice but with $\mathrm{t}=1.95$ ). In the LC model class 1 the "IN" effect is significantly positive on car and bus choice while in class 2 this effect is significantly negative on these two modes. The simulations performed both with the RPL and the LC models show that with the injunctive norm car choice would be higher by $6 \%$ in both models while air choice would be lower by $4 \%$ and $1 \%$ respectively and train choice would be lower by $1 \%$ and $4 \%$ respectively. This is to be compared to what is observed in Table 3: air choice is lower by $6 \%$ and car choice higher by $6 \%$.

In Table 7 (condition " $\mathrm{CO}_{2}+\mathrm{IN}+\mathrm{DN}$ " versus " $\mathrm{CO}_{2}+\mathrm{IN}$ ") we see that in the RPL model the "DN" effect's mean is never different from zero (despite the standard deviations being significant). In the LC model class 1 the "DN" effect is significantly negative on bus and train choice while in class 2 this effect is significantly positive on air, bus and train choice. The simulation performed with the LC model shows that with the descriptive norm air choice would be higher $(+10 \%)$ while the renouncing travel choice would be lower by $3 \%$. As shown by the sample observations in Table 3 air choice $(+3 \%)$ and car choice $(+6 \%)$ are higher, and renouncing travel choice is lower by $4 \%$.

Table 8 (condition " $\mathrm{CO}_{2}+\mathrm{IN}+$ tax" versus " $\mathrm{CO}_{2}+\mathrm{IN}$ ") shows that the "tax" framing effect is never significant in both models. Thus no simulation is performed. Nevertheless, as shown by the sample observations in Table 3 air and car choice is higher $(+6 \%)$ while bus and train choice is lower (respectively $-7 \%$ and $-5 \%$ ). 
In Table 9 (condition " $\mathrm{CO}_{2}+\mathrm{IN}+\mathrm{BM}$ " versus " $\mathrm{CO}_{2}+\mathrm{IN}$ ") we see that in the RPL model the "BM" framing effect's mean is never different from zero (despite the standard deviations being significant). In the LC model the "BM" effect is only significant and positive on car choice in class 1 . The simulation performed with the LC model shows that with the bonusmalus framing effect, car choice would be higher $(+4 \%)$ while the renouncing travel choice would be lower $(-3 \%)$. The observed change shown in Table 3 is also $+4 \%$ for car and $-3 \%$ for renouncing travel, but $-8 \%$ for bus and $+8 \%$ for train, which is not predicted by the simulation.

Finally, Table 10 (condition " $\mathrm{CO}_{2}+\mathrm{IN}+$ quotas" versus " $\mathrm{CO}_{2}+\mathrm{IN}$ ") shows that in the RPL model the "quotas" framing effect is significant and on average negative for bus choice. In the LC model class 1 the "quotas" effect is significantly positive on air and train choice and negative on bus choice. In class 2 this effect is significantly negative on air, bus and train choice. The simulations performed both with the RPL and the LC models show that with the quotas framing, air choice would be lower (-4\% and $-5 \%$ respectively) while car choice would be higher $(+10 \%$ and $+7 \%$ respectively). The observed change shown in Table 3 is $-6 \%$ for air, $+8 \%$ for car, $-7 \%$ for bus and $+3 \%$ for train. Thus the prediction is in line with the observation for air and car choice. 
Table 5: Comparison of " $\mathrm{CO}_{2}$ information" condition to control

\begin{tabular}{|c|c|c|c|c|c|c|c|c|}
\hline & \multicolumn{2}{|l|}{ MNL } & \multicolumn{2}{|l|}{ RPL } & \multicolumn{4}{|c|}{ LC } \\
\hline & & & & & Class & & Class & \\
\hline & Coefficient & $t$ & Coefficient & $t$ & Coefficient & $\mathrm{t}$ & Coefficient & $\mathrm{t}$ \\
\hline Air constant & $8.84824 * * *$ & 27.32 & $15.2634 * * *$ & 16.55 & $11.1380 * * *$ & 21.92 & $9.20021 * * *$ & 9.45 \\
\hline Car constant & $7.94344 * * *$ & 18.81 & $13.6876 * * *$ & 14.21 & $10.1512 * * *$ & 17.57 & $8.07690 * * *$ & 6.54 \\
\hline Bus constant & $6.32151 * * *$ & 9.41 & $11.5634 * * *$ & 9.42 & $7.95626 * * *$ & 6.65 & $9.76708 * * *$ & 8.23 \\
\hline Train constant & $9.00312 * * *$ & 26.64 & $15.1908 * * *$ & 16.66 & $11.0969 * * *$ & 22.07 & $9.76141 * * *$ & 9.8 \\
\hline " $\mathrm{CO}_{2} "$ air & $-0.46284 * *$ & -2.14 & $-1.94948 * *$ & -1.98 & $-1.93527^{* * *}$ & -5.16 & $-1.93527^{* * *}$ & -5.16 \\
\hline " $\mathrm{CO}_{2}$ " car & 0.33296 & 1.24 & -1.76363 & -1.52 & $-0.72160 *$ & -1.77 & -0.62689 & -0.5 \\
\hline " $\mathrm{CO}_{2} "$ bus & $0.71784 * *$ & 2.46 & -0.92342 & -0.72 & -0.71427 & -1.5 & $4.00849 * * *$ & 5.1 \\
\hline " $\mathrm{CO}_{2} "$ train & $0.93026 * * *$ & 3.89 & -0.21818 & -0.22 & $-0.86169 * *$ & -2.21 & $4.87396 * * *$ & 6.38 \\
\hline Duration air & $-0.33671 * * *$ & -16.63 & $-0.51893 * * *$ & -15.81 & $-0.41562 * * *$ & -16.28 & $-0.28185^{* * *}$ & -3.65 \\
\hline Duration car & $-0.28800 * * *$ & -9.67 & $-0.42900 * * *$ & -9.75 & $-0.35606 * * *$ & -9.95 & $-0.13165^{*}$ & -1.69 \\
\hline Duration bus & $-0.26203 * * *$ & -4.54 & $-0.45809 * * *$ & -5.36 & $-0.32739 * * *$ & -3.11 & $-0.31194 * * *$ & -3.99 \\
\hline Duration train & $-0.38234 * * *$ & -19.32 & $-0.52174 * * *$ & -16.86 & $-0.43710 * * *$ & -16.89 & $-0.28600 * * *$ & -6.17 \\
\hline Price & $-0.00791 * * *$ & -20.22 & $-0.01208 * * *$ & -17.62 & $-0.00820 * * *$ & -17.11 & $-0.01460 * * *$ & -9.52 \\
\hline $\mathrm{Sd}^{\#}$ Air const. & & & $3.69253 * * *$ & 6.37 & & & & \\
\hline Sd $^{\#}$ Car const. & & & $3.33664 * * *$ & 5.52 & & & & \\
\hline $\mathrm{Sd}^{\#}$ Bus const. & & & $3.19083 * * *$ & 4.97 & & & & \\
\hline Sd" Train const. & & & $3.46157 * * *$ & 6.04 & & & & \\
\hline $\mathrm{Sd}^{\#}$ " $\mathrm{CO}_{2}$ " air & & & $2.93593 * * *$ & 2.87 & & & & \\
\hline $\mathrm{Sd}^{\#}$ " $\mathrm{CO}_{2} " \mathrm{car}$ & & & $3.09172 * * *$ & 2.87 & & & & \\
\hline $\mathrm{Sd}^{\#}$ " $\mathrm{CO}_{2}$ " bus & & & $3.92107 * * *$ & 3.67 & & & & \\
\hline $\mathrm{Sd}^{\#}$ " $\mathrm{CO}_{2}$ " train & & & $4.09265 * * *$ & 4.42 & & & & \\
\hline Class probability & & & & & $0.84370 * * *$ & 31.92 & $0.15630 * * *$ & 5.91 \\
\hline Log-likelihood & -1692.9 & & -1413.8 & & -1543.8 & & & \\
\hline Pseudo R2 (adj) & 0.2861 & & 0.4038 & & 0.3508 & & & \\
\hline
\end{tabular}

Simulation "what if" scenario " $\mathrm{CO}_{2}$ " vs Control

$\begin{array}{lcr} & \text { RPL } & \text { LC } \\ \text { AIR } & -17 \% & -16 \% \\ \text { CAR } & 1 \% & 3 \% \\ \text { BUS } & 4 \% & 2 \% \\ \text { TRAIN } & 13 \% & 11 \% \\ \text { NONE } & 0 \% & 0 \%\end{array}$

\# Standard deviation of parameter distribution (for random parameters)

$* * *, * *, *$ : significance at $1 \%, 5 \%, 10 \%$ level. 
Table 6: Comparison of " $\mathrm{CO}_{2}+\mathrm{IN}$ " condition to " $\mathrm{CO}_{2}$ " condition

\begin{tabular}{|c|c|c|c|c|c|c|c|c|}
\hline & \multicolumn{2}{|l|}{ MNL } & \multicolumn{2}{|l|}{$\mathrm{RPL}$} & \multicolumn{4}{|c|}{ LC } \\
\hline & & & & & Class 1 & & Class & \\
\hline & Coefficient & $t$ & Coefficient & $\mathrm{t}$ & Coefficient & $\mathrm{t}$ & Coefficient & $t$ \\
\hline Air constant & $6.19669 * * *$ & 17.83 & $10.7043^{* * *}$ & 13.19 & $8.08455 * * *$ & 14.72 & $2.60990^{*}$ & 1.84 \\
\hline Car constant & $5.58387 * * *$ & 11.37 & $9.38492 * * *$ & 9.06 & $6.62484 * * *$ & 9.85 & $5.41277 * * *$ & 4.99 \\
\hline Bus constant & $6.60307 * * *$ & 9.11 & $10.5248 * * *$ & 7.88 & $6.61756 * * *$ & 5.85 & $7.99421 * * *$ & 6.58 \\
\hline Train constant & $7.00301 * * *$ & 17.32 & $12.2242 * * *$ & 13.87 & $8.98775 * * *$ & 14.9 & $6.22162 * * *$ & 6.79 \\
\hline "IN" air & -0.10837 & -0.42 & 1.95963 & 1.49 & 0.98938 & 1.6 & 1.33288 & 1.13 \\
\hline "IN" car & $0.58170 * *$ & 1.96 & $2.83929 *$ & 1.95 & $2.67904 * * *$ & 3.96 & $-2.56947 * * *$ & -3.2 \\
\hline "IN" bus & 0.10692 & 0.36 & $3.01246 * *$ & 2.06 & $1.46210^{* *}$ & 2.06 & $-1.75751 * *$ & -2.34 \\
\hline "IN" train & 0.01898 & 0.07 & 1.83847 & 1.37 & 0.38585 & 0.53 & -0.99349 & -1.56 \\
\hline Duration air & $-0.25259 * * *$ & -10.57 & $-0.44544 * * *$ & -10.99 & $-0.34972 * * *$ & -9.76 & $-0.33688 * * *$ & -3.37 \\
\hline Duration car & $-0.19155^{* * *}$ & -6.85 & $-0.34185 * * *$ & -7.69 & $-0.24845^{* * *}$ & -6.77 & $-0.14459 * *$ & -2.5 \\
\hline Duration bus & $-0.33323 * * *$ & -4.99 & $-0.58282 * * *$ & -5.49 & $-0.31992 * * *$ & -2.96 & $-0.39333 * * *$ & -4.28 \\
\hline Duration train & $-0.26201 * * *$ & -13.64 & $-0.45534 * * *$ & -13.26 & $-0.40154 * * *$ & -11.63 & $-0.17198 * * *$ & -4.92 \\
\hline Price & $-0.00500 * * *$ & -13.18 & $-0.00907 * * *$ & -13.35 & $-0.00680 * * *$ & -11.97 & $-0.00347 * * *$ & -3.66 \\
\hline $\mathrm{Sd}^{\#}$ Air const. & & & $2.71735 * * *$ & 5.02 & & & & \\
\hline Sd" Car const. & & & $3.53898 * * *$ & 6.04 & & & & \\
\hline Sd" Bus const. & & & $3.99419 * * *$ & 4.98 & & & & \\
\hline Sd ${ }^{\#}$ Train const. & & & $2.05364 * * *$ & 5.65 & & & & \\
\hline$S d^{\#}$ "IN" air & & & $3.84388 * * *$ & 4.19 & & & & \\
\hline$S d "$ "IN" car & & & $5.57109 * * *$ & 5.99 & & & & \\
\hline$S d^{\#}$ "IN" bus & & & $6.16297 * * *$ & 3.9 & & & & \\
\hline Sd" “IN" train & & & $4.16390 * * *$ & 3.85 & & & & \\
\hline Class probability & & & & & $0.68880 * * *$ & 15.7 & $0.31120 * * *$ & 7.09 \\
\hline Log-likelihood & -1358.1406 & & -1065.8 & & -1239.3 & & & \\
\hline Pseudo R2 adj. & 0.1462 & & 0.33 & & 0.2247 & & & \\
\hline
\end{tabular}

Simulation "what if" scenario " $\mathrm{CO}_{2}+\mathrm{IN} "$ vs " $\mathrm{CO}_{2} "$

\begin{tabular}{lc} 
& RPL \\
AIR & $-4 \%$ \\
CAR & $6 \%$ \\
BUS & $0 \%$ \\
TRAIN & $-1 \%$ \\
NONE & $-1 \%$ \\
\hline Standard deviation of parameter distribution (for random parameters) & $-4 \%$ \\
$* * *, * * *:$ significance at $1 \%, 5 \%, 10 \%$ level.
\end{tabular}


Table 7: Comparison of " $\mathrm{CO}_{2}+\mathrm{IN}+\mathrm{DN}$ " condition to " $\mathrm{CO}_{2}+\mathrm{IN}$ " condition

\begin{tabular}{|c|c|c|c|c|c|c|c|c|}
\hline & \multicolumn{2}{|l|}{ MNL } & \multicolumn{2}{|l|}{ RPL } & \multicolumn{4}{|c|}{ LC } \\
\hline & & & & & Class 1 & & Class 2 & \\
\hline & Coefficient & $t$ & Coefficient & $t$ & Coefficient & $\mathrm{t}$ & Coefficient & $\mathrm{t}$ \\
\hline Air constant & $5.79994 * * *$ & 16.86 & $11.9857 * * *$ & 9.59 & $8.32884 * * *$ & 12.21 & $4.74090 * * *$ & 6.27 \\
\hline Car constant & $5.93226 * * *$ & 12.37 & $11.6795 * * *$ & 8.43 & $8.06234 * * *$ & 10.08 & $5.59888 * * *$ & 4.98 \\
\hline Bus constant & 7. $35540 * * *$ & 8.19 & $12.9023 * * *$ & 7.9 & $8.92928 * * *$ & 7.01 & $7.25531 * * *$ & 4.58 \\
\hline Train constant & $6.70536 * * *$ & 16.93 & $13.3207 * * *$ & 10.05 & $9.51004 * * *$ & 13.18 & $3.94665 * * *$ & 3.62 \\
\hline “DN" air & $.94142 * * *$ & 3.05 & 0.11689 & 0.08 & -0.69446 & -1.24 & $2.73098 * * *$ & 3.11 \\
\hline “DN" car & 0.45573 & 1.36 & -0.03182 & -0.02 & -0.37761 & -0.62 & 0.83258 & 0.87 \\
\hline “DN" bus & 0.39898 & 1.14 & -1.38409 & -0.82 & $-2.89489 * * *$ & -3.69 & $3.84002 * * *$ & 3.9 \\
\hline "DN" train & $0.71131 * *$ & 2.24 & 0.03153 & 0.02 & $-1.99212 * * *$ & -3.37 & $6.03224 * * *$ & 5.63 \\
\hline Duration air & $-0.22173 * * *$ & -9.36 & $-0.40089 * * *$ & -10.5 & $-0.26943 * * *$ & -7.67 & $-0.26078 * * *$ & -4.37 \\
\hline Duration car & $-0.18158 * * *$ & -6.81 & $-0.31821 * * *$ & -8.08 & $-0.24560 * * *$ & -6.27 & $-0.12426 * *$ & -2.24 \\
\hline Duration bus & $-0.40060 * * *$ & -4.73 & $-0.54095 * * *$ & -4.91 & $-0.36167 * * *$ & -3.19 & $-0.46983 * * *$ & -3.09 \\
\hline Duration train & $-0.24049 * * *$ & -12.96 & $-0.42043 * * *$ & -12.97 & $-0.27775 * * *$ & -11.11 & $-0.27059 * * *$ & -5.85 \\
\hline Price & $-0.00483 * * *$ & -13.09 & $-0.00865 * * *$ & -13.77 & $-0.00573 * * *$ & -10.07 & $-0.00605 * * *$ & -5.63 \\
\hline $\mathrm{Sd}^{\#}$ Air const. & & & $3.72696 * * *$ & 4.23 & & & & \\
\hline Sd" Car const. & & & $5.02563 * * *$ & 4.93 & & & & \\
\hline Sd" Bus const. & & & $3.77749 * * *$ & 4.65 & & & & \\
\hline Sd $d^{\#}$ Train const. & & & $4.42091 * * *$ & 5.03 & & & & \\
\hline$S d "$ "DN" air & & & $2.64838 * * *$ & 2.62 & & & & \\
\hline $\mathrm{Sd}^{\#}$ "DN" car & & & $4.03323 * * *$ & 3.06 & & & & \\
\hline$S d "$ "DN" bus & & & $4.20110 * * *$ & 3.46 & & & & \\
\hline $\mathrm{Sd}^{\#}$ "DN" train & & & $3.10145 * * *$ & 2.96 & & & & \\
\hline Class probability & & & & & $0.71141 * * *$ & 16.16 & $0.28859 * * *$ & 6.56 \\
\hline Log-likelihood & -1337.7 & & -1085.3 & & -1228.9 & & & \\
\hline Pseudo R2 adj. & 0.1382 & & 0.3008 & & 0.2122 & & & \\
\hline $\mathrm{N}=1140$ observati & is, 190 res & dents & & & & & & \\
\hline
\end{tabular}

Simulation "what if” scenario " $\mathrm{CO}_{2}+\mathrm{IN}+\mathrm{DN}$ " vs “ $\mathrm{CO}_{2}+\mathrm{IN}$ ”

$\begin{array}{lll}\text { AIR } & \text { ns } & 10 \% \\ \text { CAR } & \text { ns } & -3 \% \\ \text { BUS } & n s & -2 \% \\ \text { TRAIN } & n \text { ns } \\ \text { NONE } & -1 \%\end{array}$

\# Standard deviation of parameter distribution (for random parameters)

$* * *, * *, *$ : significance at $1 \%, 5 \%, 10 \%$ level.

ns: no mode specific framing effect is significant 
Table 8: Comparison of " $\mathrm{CO}_{2}+\mathrm{IN}+$ tax" condition to " $\mathrm{CO}_{2}+\mathrm{IN}$ " condition

\begin{tabular}{|c|c|c|c|c|c|c|c|c|}
\hline & \multicolumn{2}{|l|}{ MNL } & \multicolumn{2}{|l|}{ RPL } & \multicolumn{4}{|c|}{$\mathrm{LC}$} \\
\hline & & & & & Class 1 & & Class & 2 \\
\hline & Coefficient & $t$ & Coefficient & $\mathrm{t}$ & Coefficient & $\mathrm{t}$ & Coefficient & $\mathrm{t}$ \\
\hline Air constant & $5.65848 * * *$ & 16.62 & $11.1727^{* * *}$ & 8.71 & $6.66045^{* * *}$ & 7.45 & $5.97026 * * *$ & 11.84 \\
\hline Car constant & $5.92542 * * *$ & 12.86 & $11.3405 * * *$ & 8.07 & $7.02444 * * *$ & 6.61 & $6.29915 * * *$ & 8.76 \\
\hline Bus constant & $5.18769 * * *$ & 9.73 & $10.0962 * * *$ & 7.37 & 2.10119 & 0.6 & $6.06454 * * *$ & 9.33 \\
\hline Train constant & $6.36034 * * *$ & 16.34 & $12.4326 * * *$ & 9.34 & $8.08424 * * *$ & 6.49 & $7.55727 * * *$ & 12.77 \\
\hline "tax" air & 0.41473 & 1.59 & 0.84801 & 0.51 & 3.17663 & 0.69 & 0.30917 & 0.89 \\
\hline "tax" car & 0.35447 & 1.26 & 1.24216 & 0.72 & 2.93694 & 0.63 & 0.60152 & 1.56 \\
\hline "tax" bus & -0.20039 & -0.56 & -0.8534 & -0.46 & 2.58009 & 0.52 & -0.06243 & -0.16 \\
\hline "tax" train & -0.03547 & -0.13 & -0.1125 & -0.07 & 1.32479 & 0.29 & -0.04274 & -0.14 \\
\hline Duration air & $-0.19162 * * *$ & -8.08 & $-0.29815 * * *$ & -8.27 & $-0.14211 * * *$ & -3.21 & $-0.26132 * * *$ & -6.69 \\
\hline Duration car & $-0.17897 * * *$ & -7.17 & $-0.31051 * * *$ & -8.07 & $-0.15024 * * *$ & -3.83 & $-0.24276 * * *$ & -5.7 \\
\hline Duration bus & $-0.18636 * * *$ & -4.45 & $-0.26795 * * *$ & -4.61 & -0.07472 & -0.33 & $-0.19891 * * *$ & -4.28 \\
\hline Duration train & $-0.20086 * * *$ & -11.33 & $-0.35069 * * *$ & -11.95 & $-0.48682 * * *$ & -3.32 & $-0.22980 * * *$ & -9.67 \\
\hline Price & $-0.00493 * * *$ & -13.12 & $-0.00854 * * *$ & -13.33 & $-0.00420 * * *$ & -6.57 & $-0.00641 * * *$ & -10.47 \\
\hline $\mathrm{Sd}^{\#}$ Air const. & & & $3.61067 * * *$ & 4.19 & & & & \\
\hline Sd" Car const. & & & $4.65298 * * *$ & 4.72 & & & & \\
\hline $\mathrm{Sd}^{\#}$ Bus const. & & & $3.41024 * * *$ & 4.22 & & & & \\
\hline Sd $d^{\#}$ Train const. & & & $3.97847 * * *$ & 4.4 & & & & \\
\hline Sd" "tax" air & & & $3.55115 * * *$ & 3.92 & & & & \\
\hline$S d^{\#}$ “tax" car & & & $4.10607 * * *$ & 4.33 & & & & \\
\hline Sd" "tax" bus & & & $2.25473 * *$ & 2.33 & & & & \\
\hline $\mathrm{Sd}^{\#}$ “tax" train & & & $3.12154 * * *$ & 3.79 & & & & \\
\hline Class probability & & & & & $0.41209 * * *$ & 9.45 & $0.58791 * * *$ & 13.49 \\
\hline Log-likelihood & -1414.1 & & -1099.2 & & -1280.4 & & & \\
\hline Pseudo R2 adj. & 0.0962 & & 0.2975 & & 0.1857 & & & \\
\hline
\end{tabular}

\# Standard deviation of parameter distribution (for random parameters)

$* * *, * *, *$ : significance at $1 \%, 5 \%, 10 \%$ level. 
Table 9: Comparison of " $\mathrm{CO}_{2}+\mathrm{IN}+\mathrm{BM}$ " condition to " $\mathrm{CO}_{2}+\mathrm{IN}$ " condition

\begin{tabular}{|c|c|c|c|c|c|c|c|c|}
\hline & \multicolumn{2}{|l|}{ MNL } & \multicolumn{2}{|l|}{ RPL } & \multicolumn{4}{|c|}{ LC } \\
\hline & & & & & Class & 1 & Class & \\
\hline & Coefficient & $t$ & Coefficient & $\mathrm{t}$ & Coefficient & $\mathrm{t}$ & Coefficient & $t$ \\
\hline Air constant & $6.05249 * * *$ & 18.85 & $11.5630 * * *$ & 9.63 & $7.37715 * * *$ & 15.38 & $4.07100 * * *$ & 5.39 \\
\hline Car constant & $5.93264 * * *$ & 13.04 & $10.9853 * * *$ & 8.19 & $6.28902 * * *$ & 9.35 & $7.00844 * * *$ & 5.89 \\
\hline Bus constant & $6.41729 * * *$ & 10.37 & $11.4584 * * *$ & 8.19 & $6.98525^{* * *}$ & 10.37 & $6.98525 * * *$ & 10.37 \\
\hline Train constant & $6.75933 * * *$ & 18.66 & $12.8038 * * *$ & 10.11 & $8.27772 * * *$ & 15.17 & $6.88963 * * *$ & 3.6 \\
\hline “BM" air & $0.67080 * *$ & 2.15 & 0.87886 & 0.42 & $0.76075^{*}$ & 1.79 & 0.4918 & 0.81 \\
\hline "BM" car & $0.85507 * * *$ & 2.6 & 1.49332 & 0.71 & $1.26321 * * *$ & 2.69 & 0.56145 & 1.06 \\
\hline "BM" bus & 0.44935 & 1.14 & -0.07629 & -0.03 & 0.3542 & 0.86 & 0.3542 & 0.86 \\
\hline "BM" train & $0.69138 * *$ & 2.18 & 1.01902 & 0.49 & 0.70657 & 1.64 & 1.42245 & 1.41 \\
\hline Duration air & $-0.23141 * * *$ & -9.56 & $-0.34697 * * *$ & -9.46 & $-0.27990 * * *$ & -9.75 & -0.02283 & -0.32 \\
\hline Duration car & $-0.16797 * * *$ & -6.61 & $-0.27335^{* * *}$ & -7.22 & $-0.19657 * * *$ & -5.15 & $-0.13456 * *$ & -2.56 \\
\hline Duration bus & $-0.29293 * * *$ & -5.47 & $-0.39589 * * *$ & -5.33 & $-0.29512 * * *$ & -4.74 & $-0.27228 * * *$ & -4.03 \\
\hline Duration train & $-0.22485^{* * *}$ & -12.85 & $-0.37339 * * *$ & -12.59 & $-0.26068 * * *$ & -12.61 & $-0.63258 * *$ & -2.02 \\
\hline Price & $-0.00520 * * *$ & -14.92 & $-0.00873 * * *$ & -14.6 & $-0.00618 * * *$ & -13.51 & $-0.00704 * * *$ & -7.05 \\
\hline $\mathrm{Sd}^{\#}$ Air const. & & & $3.60599 * * *$ & 4.2 & & & & \\
\hline Sd $^{\#}$ Car const. & & & $4.91058 * * *$ & 4.74 & & & & \\
\hline $\mathrm{Sd}^{\#}$ Bus const. & & & $3.62287 * * *$ & 4.54 & & & & \\
\hline Sd" Train const. & & & $4.20146 * * *$ & 4.81 & & & & \\
\hline$S d^{\#}$ "BM" air & & & $2.56726 * *$ & 2.41 & & & & \\
\hline$S d "$ "BM" car & & & $3.08562 * *$ & 2.19 & & & & \\
\hline$S d^{\#}$ ' $B M$ " bus & & & $3.23062 * *$ & 2.03 & & & & \\
\hline $\mathrm{Sd}^{\#}$ "BM" train & & & $2.86527 * * *$ & 2.59 & & & & \\
\hline Class probability & & & & & $0.80455 * * *$ & 21.79 & $0.19545 * * *$ & 5.29 \\
\hline Log-likelihood & -1278.6 & & -1040.1 & & -1184.2 & & & \\
\hline Pseudo R2 adj. & 0.1676 & & 0.3228 & & 0.2332 & & & \\
\hline
\end{tabular}

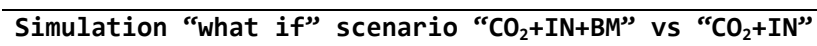

\begin{tabular}{|c|c|c|}
\hline & RPL & \\
\hline AIR & ns & $1 \%$ \\
\hline CAR & ns & $4 \%$ \\
\hline TRAIN & ns & $0 \%$ \\
\hline NONE & ns & -3 \\
\hline
\end{tabular}

\# Standard deviation of parameter distribution (for random parameters)

$* * *, * *, *$ : significance at $1 \%, 5 \%, 10 \%$ level. 
Table 10: Comparison of " $\mathrm{CO}_{2}+\mathrm{IN}+$ quotas" condition to " $\mathrm{CO}_{2}+\mathrm{IN}$ " condition

\begin{tabular}{|c|c|c|c|c|c|c|c|c|}
\hline & \multicolumn{2}{|l|}{ MNL } & \multicolumn{2}{|l|}{ RPL } & \multicolumn{4}{|c|}{$\mathrm{LC}$} \\
\hline & & & & & Class 1 & & Class 2 & \\
\hline & Coefficient & $\mathrm{t}$ & Coefficient & $\mathrm{t}$ & Coefficient & $\mathrm{t}$ & Coefficient & $\mathrm{t}$ \\
\hline Air constant & $5.40327 * * *$ & 17.2 & $10.9730 * * *$ & 8.72 & $6.32552 * * *$ & 11.12 & $6.02226 * * *$ & 8.69 \\
\hline Car constant & $4.66944 * * *$ & 10.5 & $9.18679 * * *$ & 6.69 & $5.48843 * * *$ & 7.18 & $5.12068 * * *$ & 6.08 \\
\hline Bus constant & $5.95438 * * *$ & 10.11 & $10.6640 * * *$ & 7.61 & $7.05169 * * *$ & 9.66 & $7.05169 * * *$ & 9.66 \\
\hline Train constant & $5.80155 * * *$ & 16.64 & $11.5660 * * *$ & 8.98 & $5.01341 * * *$ & 7.04 & $7.69239 * * *$ & 10.98 \\
\hline "quotas" air & -0.22146 & -0.82 & $-2.44353^{*}$ & -1.76 & $0.92207 * *$ & 1.98 & $-1.97191 * * *$ & -3.66 \\
\hline "quotas" car & 0.42516 & 1.5 & -1.20449 & -0.88 & -0.34932 & -0.68 & $0.86167^{*}$ & 1.74 \\
\hline "quotas" bus & -0.2321 & -0.67 & $-3.35895^{* *}$ & -2.09 & $-1.10219 * *$ & -2.27 & $-1.10219 * *$ & -2.27 \\
\hline "quotas" train & -0.14411 & -0.52 & -2.04421 & -1.49 & $2.51638 * * *$ & 4.31 & $-2.50463 * * *$ & -5.22 \\
\hline Duration air & $-0.20522 * * *$ & -8.35 & $-0.33310 * * *$ & -8.7 & $-0.25271 * * *$ & -6.51 & $-0.25021 * * *$ & -4.39 \\
\hline Duration car & $-0.10690 * * *$ & -4.4 & $-0.16670 * * *$ & -4.43 & $-0.11761 * * *$ & -2.92 & $-0.12732 * * *$ & -3.14 \\
\hline Duration bus & $-0.28103 * * *$ & -5.59 & $-0.34661 * * *$ & -5.11 & $-0.53239 * * *$ & -4.48 & $-0.25347 * * *$ & -4.74 \\
\hline Duration train & $-0.17946 * * *$ & -10.56 & $-0.30008 * * *$ & -11.2 & $-0.20709 * * *$ & -6.68 & $-0.21224 * * *$ & -6.83 \\
\hline Price & $-0.00434 * * *$ & -12.8 & $-0.00786 * * *$ & -13.55 & $-0.00542 * * *$ & -8.91 & $-0.00504 * * *$ & -7.8 \\
\hline $\mathrm{Sd}^{\#}$ Air const. & & & $3.62264 * * *$ & 4.25 & & & & \\
\hline Sd" Car const. & & & $4.51725 * * *$ & 4.76 & & & & \\
\hline Sd" Bus const. & & & $3.51030 * * *$ & 4.45 & & & & \\
\hline Sd $d^{\#}$ Train const. & & & $3.90570 * * *$ & 4.5 & & & & \\
\hline Sd" "quotas" air & & & $3.59262 * * *$ & 4.42 & & & & \\
\hline Sd" "quotas" car & & & $3.92130 * * *$ & 3.99 & & & & \\
\hline Sd" "quotas" bus & & & $2.05516^{*}$ & 1.9 & & & & \\
\hline Sd" "quotas" train & & & $3.37074 * * *$ & 4.26 & & & & \\
\hline Class probability & & & & & $0.52087 * * *$ & 10.17 & $0.47913 * * *$ & 9.35 \\
\hline Log-likelihood & -1336.1 & & -1049.5 & & -1213.6 & & & \\
\hline Pseudo R2 adj. & 0.1202 & & 0.3089 & & 0.2053 & & & \\
\hline
\end{tabular}

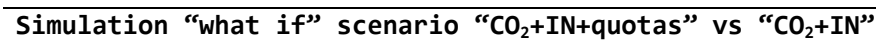

$\begin{array}{lcr} & \text { RPL } & \text { LC } \\ \text { AIR } & -4 \% & -5 \% \\ \text { CAR } & 10 \% & 7 \% \\ \text { BUS } & -3 \% & -1 \% \\ \text { TRAIN } & -3 \% & -1 \% \\ \text { NONE } & 0 \% & 0 \%\end{array}$

\# Standard deviation of parameter distribution (for random parameters)

$* * *, * *, *$ : significance at $1 \%, 5 \%, 10 \%$ level.

\section{DISCUSSION}

The potential of psychological interventions in motivating environmentally responsible behavior in a context of long distance leisure travel has been explored thanks to a series of controlled experiments testing various framing conditions: information on $\mathrm{CO}_{2}$ emissions, an injunctive and a descriptive norm, a carbon tax, a bonus-malus and a carbon trading scheme. The experiments were conducted via an Internet panel, totaling 789 
participants in the eight main French urban areas. With this experimental design and the discrete choice model specification we control the separate effects of travel price and duration on the one hand and framing conditions on the other hand.

The experimental protocol shows good consistency since travel price and duration have the expected (negative) effects on travel choice and mode choice. The results confirm the price effect (including when applicable its fiscal component) which, ceteris paribus, reduces the choice of travel and hence $\mathrm{CO}_{2}$ emissions.

There is a significant heterogeneity among respondents which is validated by the performance of both the random parameter logit models and the latent class models. However, this heterogeneity cannot easily be explained by any individual socioeconomic characteristics. This heterogeneity is even more salient in latent class models, where for one class the effect of a framing can go in one direction while in the other class this is the opposite (compare for instance in Table 10 " $\mathrm{CO}_{2}+\mathrm{IN}+$ quotas" effect for air or for train between class 1 and class 2 ).

Whatever the framing condition, in the context of our experiment, there is a preference for travelling over renouncing travel. This result should not be generalized since the respondent was incited to travel: the exact wording was "Imagine you have decided to go on holiday for one week with someone you choose". However, there is an obvious reluctance to renounce travel even in front of conditions trying to modify behavior contributing to $\mathrm{CO}_{2}$ emissions.

Overall, regarding the predictive capability of the models through simulations, when compared to the stated choices, we notice that: the " $\mathrm{CO}_{2}$ information" vs "control" model predicts correctly for air choice (but not for other modes); the " $\mathrm{CO}_{2}+$ injunctive norm" vs " $\mathrm{CO}_{2}$ " model predictions are fairly correct; the " $\mathrm{CO}_{2}+$ injunctive norm + descriptive norm" vs " $\mathrm{CO}_{2}+$ injunctive norm" model performance is mixed; the " $\mathrm{CO}_{2}+$ injunctive norm + tax" vs " $\mathrm{CO}_{2}+$ injunctive norm" model is unable to predict the stated choices; the " $\mathrm{CO}_{2}+$ injunctive norm + bonus-malus" vs " $\mathrm{CO}_{2}+$ injunctive norm" model performance is mixed; while the " $\mathrm{CO}_{2}+$ injunctive norm + quotas" vs " $\mathrm{CO}_{2}+$ injunctive norm" model predictions are fairly correct.

When it comes to the various framing conditions, the first result is that providing information on $\mathrm{CO}_{2}$ emissions has a significant effect on reducing preferences for the most emitting mode, air, by 16-17\%, while it favors a less emitting mode, train, by $11-13 \%$. This indicates that people are willing to accept to pay more or to spend more time during their journey in order to reduce $\mathrm{CO}_{2}$ emissions. It should be noted that the choice format made $\mathrm{CO}_{2}$ both salient and aligned across choices, thus facilitating discrimination of choices along the $\mathrm{CO}_{2}$ dimension. This could partly explain the significant effect of $\mathrm{CO}_{2}$ information.

The injunctive norm may reinforce the effect of $\mathrm{CO}_{2}$ information in the case of air but only slightly (between $1 \%$ and $4 \%$ ). The injunctive norm was referred to scientists, considered as the "authority" (as in Pangbourne et al, 2020, who refer to "doctors and scientists"). However, adding a descriptive norm to the injunctive norm looks obviously counterproductive, by increasing air choice and decreasing renouncing travel. Given the national scope of our study the reference of the descriptive norm to "French people" is considered as relevant. It should be noted that in their study of messages to promote walking Pangbourne et al found that the types of argument used such as "authority" (similar to injunctive norm) or "ad populum" (similar to descriptive norm) had no effect on the perceived persuasiveness of messages.

Regarding the unexpected effect of the descriptive norm one reason could be that saying that $60 \%$ are making an effort means that $40 \%$ are making no effort, which is somewhat important and might undermine the intended effect of the norm (as exemplified by Cialdini, 2003, in another context). Another reason could be that the respondents might have not trusted the descriptive statement. It might be considered as an old value (coming from 
Eurobarometer, 2008) but we could not find more recent values of this kind at the time of the survey and we could expect since an increase of the percentage of those engaged in personal actions for the environment. Finally, the formulation was quite vague and referring to environment in general. According to Keizer and Schultz (2018) the descriptive norm should have referred to beliefs about the common behavior in the specific setting of mobility. This is first limitation in our study. For future research on this point a better formulation of the descriptive norm would be needed, with the following criteria: a mobility context, a trustworthy statement and a large majority of compliant people.

While the price effect itself is significant (as measured through the price covariate), a fiscal framing with the carbon tax has no significant effect on its own. It is as if once the social cost of $\mathrm{CO}_{2}$ is internalized in the price the framing adds itself no influence.

Unexpectedly the effect of bonus-malus framing (which as said previously conveys an implicit social norm) is to increase the choice of car and not meaningfully change the choice of air when compared with the " $\mathrm{CO}_{2}$ information + injunctive norm" condition. We can see there a potential crowding out effect attached to the reward (bonus) which overcomes the bonus-malus specific social norm effect.

The quota framing goes to the same direction of reducing air choice beyond the effect of $\mathrm{CO}_{2}$ information + injunctive norm, but - while significant - the influence of this framing beyond the price effect is moderate (4-5\%). This is in line with previous literature yielding mixed conclusions about the specific effectiveness of quota schemes. However, compared to previous stated preferences studies (Parag et al, 2011; Zanni et al, 2013; Raux et al, 2015) our study strengthens this conclusion since it is based on a discrete choice method controlling explicitly for the respective influences of the context (varying travel price and duration) and framing conditions.

An unexpected result is the significant increase in car choice in the injunctive norm condition and the two fiscal framing conditions of bonus-malus and personal carbon trading despite it is the second most emitting mode - as an apparent substitute for air. As said above there is an obvious reluctance to renounce travel. One interpretation is that given the one week duration of vacation, people would accept to renounce air travel but switch to car and accept to spend time driving in order to benefit from the availability of the car for local mobility at destination. This opportunity is not offered with bus or train. This last aspect was not covered in our survey and this is a second limitation.

A third limitation of our study, which is a one-off survey, is that we do not address the issue of managing a personal allocation of quotas over a period of e.g. one year. By randomizing the amount (i.e. threshold) of quotas available across the individuals, the design mimics the varying amount of quotas left to the individual at different times in the year. However this does not cover the issue of trading-off the quotas budget over the period nor measure the potential nudging effect of carbon account feedback on successive consumer decisions. Tackling this issue would have called for another study specific to the quota scheme. Nevertheless, despite this limitation a framing effect of quotas scheme is found significant though moderate.

Finally, a fourth limitation of our study is that respondents were not facing the real consequences of their choices (i.e. by making the responses "incentive compatible" like e.g. paying actually at least something for their chosen travel) yielding what is denoted as "hypothetical bias" (for a discussion of this issue see Harrison, 2014). Here again implementing incentive compatibility would have implied another study design with resources beyond scope. 


\section{CONCLUSION}

Overall, the intrinsic motivation to reduce $\mathrm{CO}_{2}$ emissions through one's own mobility choices seems to be activated by providing information on emissions from travel alternatives. Providing information on $\mathrm{CO}_{2}$ emissions significantly reduces preferences for the most emitting mode (air) and favors a less emitting mode (train). This effect is only slightly reinforced by the injunctive norm in the case of air travel. Framing the price effect as a bonusmalus seems to generate a crowding out effect high enough to overcome the social norm effect attached to the bonus-malus. On the other hand framing the price effect through a PCT/quota scheme yields a lower crowding out effect which does not overcome the social norm effect attached to the quotas.

The basic policy implication of such results is that providing $\mathrm{CO}_{2}$ emissions information on each travel alternative - as already done with some online emissions comparisons of travel alternatives - is likely to yield actual behavior changes. Pricing (including the internalization of social cost of $\mathrm{CO}_{2}$ through fiscal incentives) have the expected effects of reducing the choice of travelling and hence $\mathrm{CO}_{2}$ emissions. Framing the fiscal incentive as personal carbon trading reinforces (but moderately) the fiscal effect in reducing air choice.

A first research perspective would be to understand the underlying heterogeneity in responses to various framings through larger samples. A second one would be to improve the experimental design in view of the recent results of Walker et al (2018) regarding the robustness of various designs. A third one would be to specify the design of these schemes in their various distributional aspects in order to explore if this would increase their effectiveness in changing behavior. There is a need to pursue this line of research if we want to successfully implement effective and acceptable carbon pricing schemes in the transport sector.

\section{REFERENCES}

ADEME, 2008. Efficacités énergétique et environnementale des modes de transport. Janvier 2008, $29 \mathrm{p}$.

Ajzen, I., 1991. The theory of planned behavior. Organizational Behavior and Human Decision Processes, 50, 179-211.

Baumol, W., Oates, W., 1988. The theory of environmental policy. Cambridge University Press, Cambridge, 299p.

Bristow, A., Wardman, M., Zanni, A., Chintakayala P., 2010. Public acceptability of personal carbon trading and carbon tax. Ecological Economics 69 (2010) 1824-1837.

Capstick, S., Lewis, A., 2009. Personal Carbon Allowances: A Pilot Simulation and Questionnaire. UKERC, Oxford, $88 \mathrm{p}$.

CGSP, 2013. Evaluation socioéconomique des investissements publics. Rapport de la commission présidée par Emile Quinet. Commissariat Général à la Stratégie et à la Prospective. Tome 2, Valeurs du temps. http://www.strategie.gouv.fr/

ChoiceMetrics, 2014. Ngene 1.1.2 User Manuel \& Reference Guide. www.choicemetrics.com

Cialdini, R., 2003. Crafting Normative Messages to Protect the Environment. Current Directions in Psychological Science, 12, 105-109

Cialdini, R.B., Kallgren, C.A., Reno, R.R., 1991. A focus theory of normative conduct. Advances in Experimental Social Psychology, 24, 201-234.

D’Haultfoeuille, X., Durrmeyer, I., Février, P., 2011. Le coût du bonus/malus écologique: que pouvait-on prédire? Revue Economique, 62, 491-499. 
Davison, L., Littleford, C., Ryley T., 2014. Air travel attitudes and behaviours: The development of environment-based segments. Journal of Air Transport Management 36 (2014) 13-22.

De Borger, B., Fosgerau, M., 2008. The trade-off between money and travel time: A test of the theory of reference-dependent preferences. Journal of Urban Economics 64 (2008) $101-115$

Eurobarometer, 2008. Special Eurobarometer. Attitudes of European citizens towards the environment Fieldwork: November - December 2007 Publication: March 2008. European Commission.

Fallah Zavareh, M., Mehdizadeh, M., Nordfjærn, T., 2020. Active travel as a proenvironmental behaviour: An integrated framework. Transportation Research Part D 84 (2020). DOI: 10.1016/j.trd.2020.102356

Fawcett, T., 2010. Personal carbon trading: A policy ahead of its time? Energy Policy (2010), doi:10.1016/ j.enpol.2010.07.001

Fleming, D., 1996. Stopping the traffic. Country Life 140 (19), 62-65 (see also www.dtqs.org)

Frey, B., 1997. Not just for the money: An economic theory of personal motivation. Cheltenham: Edward Elgar.

Frey, B., Stutzer, A., 2008. Environmental morale and motivation. In A. Lewis (ed.). Psychology and economic behavior. Cambridge: Cambridge University Press (pp. 406-428).

Goulder, L., Parry, I., 2008. Instrument Choice in Environmental Policy. Review of Environmental Economics and Policy, volume 2, issue 2, summer 2008, pp. 152-174

Greene, D.L., Patterson, P.D., Singh, M., Li, J., 2005. Feebates, rebates and gas-guzzler taxes: a study of incentives for increased fuel economy. Energy Policy 33 (2005) 757-775

Greene, W.H., Hensher, D.A., 2003. A latent class model for discrete choice analysis: contrasts with mixed logit. Transportation Research Part B 37 (2003) 681-698

Greene, W.H., Hensher, D.A., 2010. Does scale heterogeneity across individuals matter? An empirical assessment of alternative logit models. Transportation, vol. 37(3), pages 413-428, May. DOI: 10.1007/s11116-010-9259-z

Harrison, G.W., 2014. Real choices and hypothetical choices. In Handbook of Choice Modelling. Hess, S., Daly, A. (eds). Edward Elgar, Cheltenham, pp. 235-254.

Hensher, D.A., Greene, W.H., 2003. The Mixed Logit model: The state of practice. Transportation 30: 133-176.

Hensher, D.A., Rose, J.M., Greene, W.H., 2015. Applied Choice Analysis. Second Edition. Cambridge University Press.

Hess, S., 2014. Latent class structures: Taste heterogeneity and beyond. In S Hess, A.J. Daly (eds): Handbook of Choice Modelling, Edward Elgar, Editors, pp.311-329. DOI: 10.4337/9781781003152.00021

Hess, S., Ben-Akiva, M., Gopinath, D., Walker, J., 2009. Advantages of latent class models over continuous mixed logit. Paper presented at the 12th International Conference on Travel Behaviour Research, Jaipur, India.

Hess, S., Rose, J.M., Polak, J.W., 2010. Non-Trading, lexicographic and inconsistent behaviour in stated choice data. Transportation Research Part D, 15 (7). $405-417$.

Hilton, D., Charalambides, L., Demarque, C., Waroquier, L., Raux, C., 2014. A tax can nudge: The impact of an environmentally motivated bonus/malus fiscal system on transport preferences. Journal of Economic Psychology 42 (2014) 17-27

Horowitz, J.K., McConnell, K.E., 2002. A Review of WTA / WTP Studies. Journal of Environmental Economics and Management 44, 426-447. 
Howarth, C., Waterson, B., McDonald, M., 2010. Are European climate change awareness campaigns targeting correctly to encourage sustainable travel? European Transport Conference, Glasgow, October 2010

Hunecke, M., Haustein, S., Grischkat, S., Böhler, S., 2007. Psychological, sociodemographic, and infrastructural factors as determinants of ecological impact caused by mobility behavior. Journal of Environmental Psychology 27 (2007) 277-292

IEA, 2018. $\mathrm{CO}_{2}$ Emissions from fuel combustion

INSEE, 2016. Insee Résultats, $\mathrm{n}^{\circ} 180$.

Keizer, K., Schultz, P.W., 2020. Social Norms and Pro-Environmental Behaviour. In Environmental Psychology (eds L. Steg and J.I.M. Groot), pp. 153-163. doi:10.1002/9781119241072.ch18

Kormos, C., Gifford, R., Brown, E., 2015. The Influence of Descriptive Social Norm Information on Sustainable Transportation Behavior: A Field Experiment. Environment and Behavior, 2015, Vol. 47(5) 479-501.

Lancsar, E., Fiebig, D.G., Hole, A.R., 2017. Discrete Choice Experiments: A Guide to Model Specification, Estimation and Software. PharmacoEconomics. Volume 35, Issue 7, pp 697-716. https://doi.org/10.1007/s40273-017-0506-4

Louviere, J., Hensher, D., Swait, J., 2000. Stated choice methods: analysis and applications. Cambridge University Press

Mackie, P.J., Wardman, M., Fowkes, A.S., Whelan, G., Nellthorp, J., Bates, J., 2003. Values of Travel Time Savings in the UK. Report to Department for Transport. Institute of Transport Studies, University of Leeds. http://eprints.whiterose.ac.uk/2079/

McFadden, D., 1973. Conditional logit analysis of qualitative choice behaviour, in Zarembka, P., Frontiers in Econometrics, Academic Press, New York, pp.105-142.

Monchambert, G., 2020. Why do (or don't) people carpool for long distance trips? A discrete choice experiment in France. Transportation Research Part A 132 (2020) 911-931.

OECD, 2018. Effective carbon rates Pricing Carbon Emissions Through Taxes and Emissions Trading. 92 p. https://doi.org/10.1787/9789264305304-en

Pangbourne, K., Bennett, S., Baker, A., 2020. Persuasion profiles to promote pedestrianism: Effective targeting of active travel messages. Travel Behaviour and Society 20 (2020) 300-312

Parag, Y., Capstick, S., Poortinga, W., 2011. Policy Attribute Framing: A Comparison Between Three Policy Instruments for Personal Emissions Reduction. Journal of Policy Analysis and Management, Vol. 30, No. 4, 889-905.

Parry, I.W.H., Walls, M., Harrington, W., 2007. Automobile Externalities and Policies. Discussion Paper 06-26. Resources For the Future, Washington, 37 p.

Raux, C., 2011. Downstream Emissions Trading for Transport. In Rotthengatter, W., Hayashi, Y., Schade, W. (eds) Transport Moving to Climate Intelligence: New Chances for Controlling Climate Impacts of Transport after the Economic Crisis. Springer, pp. 209-226.

Raux, C., Croissant, Y., Pons, D., 2015. Would personal carbon trading reduce travel emissions more effectively than a carbon tax? Transportation Research Part D 35 (2015) 72-83

Raux, C., Marlot, G., 2005. A System of Tradable $\mathrm{CO}_{2}$ Permits Applied to Fuel Consumption by Motorists. Transport Policy, 12 (2005) 255-265.

Rose, J.M., Bliemer, M.C.J., 2005. Sample Optimality in the Design of Stated Choice Experiments, Working paper ITLS-WP-05-13. Institute of Transport and Logistics Studies, The University of Sydney, Sydney.

Rose, J.M., Bliemer, M.C.J., 2013. Sample size requirements for stated choice experiments. Transportation (2013) 40:1021-1041 
Schwartz, S. H., 1977. Normative influences on altruism. In L. Berkowitz (Ed.), Advances in experimental social psychology, Vol. 10 (pp. 221-279). New York: Academic Press.

Starkey, R., 2012a. Personal carbon trading: A critical survey. Part 1: Equity. Ecological Economics 73 (2012) 7-18.

Starkey, R., 2012b. Personal carbon trading: A critical survey. Part 2: Efficiency and effectiveness. Ecological Economics 73 (2012) 19-28.

Steg, L., Vlek, C., 2009. Encouraging pro-environmental behaviour: An integrative review and research agenda. Journal of Environmental Psychology 29 (2009) 309-317

Train, K.E., 2009. Discrete Choice Methods with Simulation. Second Edition. Cambridge University Press.

Wadud, Z., Chintakayala, P.K., 2019. Personal Carbon Trading: Trade-off and Complementarity Between In-home and Transport Related Emissions Reduction. Ecological Economics 156 (2019) 397-408

Walker, J.L., Wang, Y., Thorhauge, M., Ben-Akiva, M., 2018. D-efficient or deficient? A robustness analysis of stated choice experimental designs. Theory Dec. (2018) 84:215238. https://doi.org/10.1007/s11238-017-9647-3

Wall, R., Devine-Wright, P., Mill, G., 2007. Comparing and Combining Theories to Explain Proenvironmental Intentions. The Case of Commuting-Mode Choice. Environment and Behavior, Volume 39 Number 6

Zanni, A.M., Bristow, A.L., Wardman, M., 2013. The potential behavioural effect of personal carbon trading: results from an experimental survey. Journal of Environmental Economics and Policy, vol. 2, No. 2, 222-243. 


\section{APPENDIX}

\section{Appendix A: Examples of information displayed in the various framing conditions}

\section{Control}

You travel with another person to a destination of your choice, located 1,000 km from home. Here is a first transport situation that is offered to you:

\begin{tabular}{|l|r|r|r|r|}
\hline & Train & Air & Bus & Car* \\
\hline Duration (one way) $* *$ & $5 \mathrm{~h}$ & $3 \mathrm{~h}$ & $10 \mathrm{~h}$ & $17 \mathrm{~h}$ \\
\hline Price (return for two persons) & $600 €$ & $700 €$ & $500 €$ & $400 €$ \\
\hline
\end{tabular}

* For the car, the price takes into account the fuel and road tolls

** For air, bus or train, travel time includes the waiting time during connections

Based on this information, and not taking account of your previous answers, what means of transportation do you choose? You also have the choice of renouncing travel.

- Train

- Air

- Bus

- Car

- Renounce travel

\section{Condition 1: CO2 information}

You travel with another person to a destination of your choice, located 1,000 km from home. Here is a first transport situation that is offered to you:

\begin{tabular}{|l|r|r|r|r|}
\hline & Air & Bus & Car* & Train \\
\hline Duration (one way) ** & $5 \mathrm{~h}$ & $17 \mathrm{~h}$ & $10 \mathrm{~h}$ & $17 \mathrm{~h}$ \\
\hline Price (return for two persons) & $600 €$ & $500 €$ & $500 €$ & $400 €$ \\
\hline CO $_{2}$ emitted (return for two persons) & $720 \mathrm{~kg}$ & $124 \mathrm{~kg}$ & $408 \mathrm{~kg}$ & $180 \mathrm{~kg}$ \\
\hline
\end{tabular}

* For the car, the price takes into account the fuel and road tolls

** For air, bus or train, travel time includes the waiting time during connections

For your information: $\mathrm{CO}_{2}$ is a greenhouse gas emitted during the transport by the vehicle used (air, car, bus or train). It is computed for two persons for a return trip.

Based on this information, and not taking account of your previous answers, what means of transportation do you choose? You also have the choice of renouncing travel...

\section{Condition 2: CO2 information + Injunctive norm}

You travel with another person to a destination of your choice, located 1,000 km from home. Here is a first transport situation that is offered to you:

\begin{tabular}{|l|r|r|r|r|}
\hline & Air & Bus & Car* & Train \\
\hline Duration (one way) $* *$ & $5 \mathrm{~h}$ & $17 \mathrm{~h}$ & $10 \mathrm{~h}$ & $17 \mathrm{~h}$ \\
\hline
\end{tabular}




\begin{tabular}{|l|r|r|r|r|}
\hline Price (return for two persons) & $600 €$ & $500 €$ & $500 €$ & $400 €$ \\
\hline $\mathrm{CO}_{2}$ emitted (return for two persons) & $720 \mathrm{~kg}$ & $124 \mathrm{~kg}$ & $408 \mathrm{~kg}$ & $180 \mathrm{~kg}$ \\
\hline
\end{tabular}

* For the car, the price takes into account the fuel and road tolls

** For air, bus or train, travel time includes the waiting time during connections

For your information: $\mathrm{CO}_{2}$ is a greenhouse gas emitted during the transport by the vehicle used (air, car, bus or train). It is computed for two persons for a return trip.

The high level of greenhouse gas emissions in the atmosphere ( dangerous climate change for the planet. Climatologists are already seeing many consequences such as melting glaciers or ice fields. According to scientists, to limit these effects it is necessary that the whole humans reduce their emissions by half.

Based on this information, and not taking account of your previous answers, what means of transportation do you choose? You also have the choice of renouncing travel...

\section{Condition 3: CO2 information + Injunctive norm + Descriptive norm}

You travel with another person to a destination of your choice, located 1,000 km from home. Here is a first transport situation that is offered to you:

\begin{tabular}{|l|r|r|r|r|}
\hline & Air & Bus & Car* & Train \\
\hline Duration (one way) $* *$ & $5 \mathrm{~h}$ & $17 \mathrm{~h}$ & $10 \mathrm{~h}$ & $17 \mathrm{~h}$ \\
\hline Price (return for two persons) & $600 €$ & $500 €$ & $500 €$ & $400 €$ \\
\hline CO $_{2}$ emitted (return for two persons) & $720 \mathrm{~kg}$ & $124 \mathrm{~kg}$ & $408 \mathrm{~kg}$ & $180 \mathrm{~kg}$ \\
\hline
\end{tabular}

* For the car, the price takes into account the fuel and road tolls

** For air, bus or train, travel time includes the waiting time during connections

For your information: $\mathrm{CO}_{2}$ is a greenhouse gas emitted during the transport by the vehicle used (air, car, bus or train). It is computed for two persons for a return trip.

The high level of greenhouse gas emissions in the atmosphere ( $\operatorname{such}$ as $\mathrm{CO}_{2}$ ) can cause dangerous climate change for the planet. Climatologists are already seeing many consequences such as melting glaciers or ice fields. According to scientists, to limit these effects it is necessary that the whole humans reduce their emissions by half.

$60 \%$ of French people personally contribute through their daily actions to reducing their emissions.

Based on this information, and not taking account of your previous answers, what means of transportation do you choose? You also have the choice of renouncing travel...

\section{Condition 4: CO2 information + Injunctive norm + Tax scheme}

$\mathrm{CO}_{2}$ is a greenhouse gas emitted during the transport by the vehicle used (air, car, bus or train).

The high level of greenhouse gas emissions in the atmosphere (such as $\mathrm{CO}_{2}$ ) can cause dangerous climate change for the planet. Climatologists are already seeing many consequences such as melting glaciers or ice fields. According to scientists, to limit these effects it is necessary that the whole humans reduce their emissions by half.

To reduce these emissions, a tax is set up calculated on the basis of the quantity of $\mathrm{CO}_{2}$ emitted. It is paid by the travelers. 
You travel with another person to a destination of your choice, located 1,000 km from home. Here is a first transport situation that is offered to you:

\begin{tabular}{|l|r|r|r|r|}
\hline & Train & Air & Bus & Car* \\
\hline Duration (one way) ** & $17 \mathrm{~h}$ & $5 \mathrm{~h}$ & $17 \mathrm{~h}$ & $10 \mathrm{~h}$ \\
\hline Price (return for two persons) & $400 €$ & $600 €$ & $400 €$ & $600 €$ \\
\hline $\mathbf{C O}_{2}$ emitted (return for two persons) & $180 \mathrm{~kg}$ & $720 \mathrm{~kg}$ & $124 \mathrm{~kg}$ & $408 \mathrm{~kg}$ \\
\hline Unit amount tax per kg of CO $\mathbf{C}_{2}$ & $0.03 €$ & $0.03 €$ & $0.03 €$ & $0.03 €$ \\
\hline Total CO2 tax & $5 €$ & $22 €$ & $4 €$ & $12 €$ \\
\hline Total price (including CO2 tax) & $405 €$ & $622 €$ & $404 €$ & $612 €$ \\
\hline
\end{tabular}

* For the car, the price takes into account the fuel and road tolls

** For air, bus or train, travel time includes the waiting time during connections

Based on this information, and not taking account of your previous answers, what means of transportation do you choose? You also have the choice of renouncing travel...

\section{Condition 5: CO2 information + Injunctive norm + Bonus/malus scheme}

$\mathrm{CO}_{2}$ is a greenhouse gas emitted during the transport by the vehicle used (air, car, bus or train).

The high level of greenhouse gas emissions in the atmosphere (such as $\mathrm{CO}_{2}$ ) can cause dangerous climate change for the planet. Climatologists are already seeing many consequences such as melting glaciers or ice fields. According to scientists, to limit these effects it is necessary that the whole humans reduce their emissions by half.

To reduce these emissions, a bonus/malus scheme is set up to reward those who pollute less (bonus) and penalize those who pollute more (malus), compared with a threshold set for each return trip. The bonus/malus is calculated on the basis of the quantity of $\mathrm{CO}_{2}$ emitted beyond the threshold.

You travel with another person to a destination of your choice, located 1,000 km from home. Here is a first transport situation that is offered to you:

\begin{tabular}{|c|c|c|c|c|}
\hline & Air & Bus & Car* & Train \\
\hline Duration (one way) ** & $10 \mathrm{~h}$ & $17 \mathrm{~h}$ & $17 \mathrm{~h}$ & $10 \mathrm{~h}$ \\
\hline Price (return for two persons) & $600 €$ & $600 €$ & $400 €$ & $700 €$ \\
\hline $\mathrm{CO}_{2}$ emitted (return for two persons) & $720 \mathrm{~kg}$ & $124 \mathrm{~kg}$ & $408 \mathrm{~kg}$ & $180 \mathrm{~kg}$ \\
\hline Threshold level ( $\mathrm{kg}$ of $\left.\mathrm{CO}_{2}\right)$ & $150 \mathrm{~kg}$ & $150 \mathrm{~kg}$ & $150 \mathrm{~kg}$ & $150 \mathrm{~kg}$ \\
\hline Unit cost bonus/malus per $\mathrm{kg}$ of $\mathrm{CO}_{2}$ & $0.05 €$ & $0.05 €$ & $0.05 €$ & $0.05 €$ \\
\hline $\begin{array}{l}\text { Total bonus (price decrease) or malus } \\
\text { (price increase) }\end{array}$ & $29 €$ & $-1 €$ & $13 €$ & $2 €$ \\
\hline Total price (including bonus/malus) & $629 €$ & $599 €$ & $413 €$ & $702 €$ \\
\hline
\end{tabular}

* For the car, the price takes into account the fuel and road tolls

** For air, bus or train, travel time includes the waiting time during connections 
Based on this information, and not taking account of your previous answers, what means of transportation do you choose? You also have the choice of renouncing travel...

\section{Condition 6: CO2 information + Injunctive norm + Quotas scheme}

$\mathrm{CO}_{2}$ is a greenhouse gas emitted during the transport by the vehicle used (air, car, bus or train).

The high level of greenhouse gas emissions in the atmosphere (such as $\mathrm{CO}_{2}$ ) can cause dangerous climate change for the planet. Climatologists are already seeing many consequences such as melting glaciers or ice fields. According to scientists, to limit these effects it is necessary that the whole humans reduce their emissions by half.

To reduce these emissions, a scheme of individual quotas of emission is set up. Your annual available quota is reduced according to the travel means you use during the year. If you exceed your available quota you must buy additional emission rights, at a price fixed by the public authority. The price of these rights adds to the cost of travel. You can also sell unused rights.

You travel with another person to a destination of your choice, located 1,000 km from home. Here is a first transport situation that is offered to you:

\begin{tabular}{|l|r|r|r|r|}
\hline & Bus & Train & Car* & Air \\
\hline Duration (one way) ** & $17 \mathrm{~h}$ & $5 \mathrm{~h}$ & $17 \mathrm{~h}$ & $10 \mathrm{~h}$ \\
\hline Price (return for two persons) & $600 €$ & $700 €$ & $400 €$ & $600 €$ \\
\hline CO $_{2}$ emitted (return for two persons) & $124 \mathrm{~kg}$ & $180 \mathrm{~kg}$ & $408 \mathrm{~kg}$ & $720 \mathrm{~kg}$ \\
\hline Available quotas (kg of CO, & $500 \mathrm{~kg}$ & $500 \mathrm{~kg}$ & $500 \mathrm{~kg}$ & $500 \mathrm{~kg}$ \\
\hline Quotas to buy (+) or to be sold (-) & $-376 \mathrm{~kg}$ & $-320 \mathrm{~kg}$ & $-92 \mathrm{~kg}$ & $220 \mathrm{~kg}$ \\
\hline Unit cost quota per kg of CO, & $0.05 €$ & $0.05 €$ & $0.05 €$ & $0.05 €$ \\
\hline $\begin{array}{l}\text { Total quotas price to buy (+) or to be } \\
\text { sold (-) }\end{array}$ & $-19 €$ & $-16 €$ & $-5 €$ & $11 €$ \\
\hline $\begin{array}{l}\text { Total price (with quotas included or } \\
\text { deducted) }\end{array}$ & $581 €$ & $684 €$ & $395 €$ & $611 €$ \\
\hline
\end{tabular}

* For the car, the price takes into account the fuel and road tolls

** For air, bus or train, travel time includes the waiting time during connections

Based on this information, and not taking account of your previous answers, what means of transportation do you choose? You also have the choice of renouncing travel... 


\section{Appendix B}

Table 11: Main socio economic attributes of the sample

\begin{tabular}{|c|c|c|c|c|c|c|c|c|}
\hline Conditions & Control & 1 & 2 & 3 & 4 & 5 & 6 & Total \\
\hline $\mathrm{N}$ & 229 & 97 & 93 & 97 & 94 & 94 & 85 & 789 \\
\hline \multicolumn{9}{|l|}{ Gender } \\
\hline Male & $48 \%$ & $48 \%$ & $49 \%$ & $48 \%$ & $51 \%$ & $48 \%$ & $48 \%$ & $49 \%$ \\
\hline Female & $52 \%$ & $52 \%$ & $51 \%$ & $52 \%$ & $49 \%$ & $52 \%$ & $52 \%$ & $51 \%$ \\
\hline Total & $100 \%$ & $100 \%$ & $100 \%$ & $100 \%$ & $100 \%$ & $100 \%$ & $100 \%$ & $100 \%$ \\
\hline \multicolumn{9}{|l|}{ Residential zone* } \\
\hline Paris & $58 \%$ & $58 \%$ & $56 \%$ & $57 \%$ & $57 \%$ & $57 \%$ & $59 \%$ & $57 \%$ \\
\hline Lyon & $10 \%$ & $10 \%$ & $10 \%$ & $10 \%$ & $11 \%$ & $10 \%$ & $13 \%$ & $10 \%$ \\
\hline Aix-Marseille & $7 \%$ & $8 \%$ & $9 \%$ & $8 \%$ & $9 \%$ & $9 \%$ & $6 \%$ & $8 \%$ \\
\hline Toulouse & $6 \%$ & $6 \%$ & $6 \%$ & $6 \%$ & $6 \%$ & $5 \%$ & $6 \%$ & $6 \%$ \\
\hline Lille & $4 \%$ & $4 \%$ & $5 \%$ & $5 \%$ & $4 \%$ & $5 \%$ & $5 \%$ & $5 \%$ \\
\hline Bordeaux & $6 \%$ & $5 \%$ & $4 \%$ & $5 \%$ & $5 \%$ & $5 \%$ & $4 \%$ & $5 \%$ \\
\hline Nice & $4 \%$ & $4 \%$ & $5 \%$ & $4 \%$ & $3 \%$ & $4 \%$ & $5 \%$ & $4 \%$ \\
\hline Nantes & $4 \%$ & $4 \%$ & $4 \%$ & $4 \%$ & $4 \%$ & $4 \%$ & $4 \%$ & $4 \%$ \\
\hline Total & $100 \%$ & $100 \%$ & $100 \%$ & $100 \%$ & $100 \%$ & $100 \%$ & $100 \%$ & $100 \%$ \\
\hline \multicolumn{9}{|l|}{ Age_class } \\
\hline under 35 & $23 \%$ & $20 \%$ & $16 \%$ & $20 \%$ & $23 \%$ & $22 \%$ & $24 \%$ & $21 \%$ \\
\hline $35-44$ & $25 \%$ & $27 \%$ & $27 \%$ & $26 \%$ & $23 \%$ & $27 \%$ & $25 \%$ & $26 \%$ \\
\hline $45-59$ & $35 \%$ & $35 \%$ & $34 \%$ & $34 \%$ & $36 \%$ & $34 \%$ & $32 \%$ & $35 \%$ \\
\hline over 60 & $16 \%$ & $19 \%$ & $23 \%$ & $21 \%$ & $17 \%$ & $17 \%$ & $20 \%$ & $18 \%$ \\
\hline Total & $100 \%$ & $100 \%$ & $100 \%$ & $100 \%$ & $100 \%$ & $100 \%$ & $100 \%$ & $100 \%$ \\
\hline \multicolumn{9}{|l|}{ Status } \\
\hline Working or seeking work & $74 \%$ & $67 \%$ & $72 \%$ & $71 \%$ & $69 \%$ & $74 \%$ & $75 \%$ & $72 \%$ \\
\hline Student & $1 \%$ & $1 \%$ & $1 \%$ & $0 \%$ & $1 \%$ & $0 \%$ & $1 \%$ & $1 \%$ \\
\hline Retired & $19 \%$ & $23 \%$ & $22 \%$ & $21 \%$ & $22 \%$ & $20 \%$ & $18 \%$ & $20 \%$ \\
\hline Other & $6 \%$ & $9 \%$ & $5 \%$ & $8 \%$ & $7 \%$ & $5 \%$ & $6 \%$ & $7 \%$ \\
\hline Total & $100 \%$ & $100 \%$ & $100 \%$ & $100 \%$ & $100 \%$ & $100 \%$ & $100 \%$ & $100 \%$ \\
\hline \multicolumn{9}{|l|}{ Driving license } \\
\hline Yes & $92 \%$ & $93 \%$ & $92 \%$ & $92 \%$ & $94 \%$ & $88 \%$ & $91 \%$ & $92 \%$ \\
\hline No & $8 \%$ & $7 \%$ & $8 \%$ & $8 \%$ & $6 \%$ & $12 \%$ & $9 \%$ & $8 \%$ \\
\hline Total & $100 \%$ & $100 \%$ & $100 \%$ & $100 \%$ & $100 \%$ & $100 \%$ & $100 \%$ & $100 \%$ \\
\hline \multicolumn{9}{|l|}{ Personal monthly income class } \\
\hline less than 1200 euros & $25 \%$ & $29 \%$ & $15 \%$ & $21 \%$ & $28 \%$ & $18 \%$ & $28 \%$ & $24 \%$ \\
\hline between 1200 and 1800 euros & $23 \%$ & $25 \%$ & $27 \%$ & $33 \%$ & $29 \%$ & $28 \%$ & $29 \%$ & $27 \%$ \\
\hline between 1800 and 2600 euros & $24 \%$ & $22 \%$ & $28 \%$ & $23 \%$ & $14 \%$ & $28 \%$ & $22 \%$ & $23 \%$ \\
\hline more than 2600 euros & $28 \%$ & $25 \%$ & $29 \%$ & $23 \%$ & $28 \%$ & $26 \%$ & $20 \%$ & $26 \%$ \\
\hline Total & $100 \%$ & $100 \%$ & $100 \%$ & $100 \%$ & $100 \%$ & $100 \%$ & $100 \%$ & $100 \%$ \\
\hline
\end{tabular}

* the share of the sample in each urban area follows the share of its population in the total living in the eight urban areas (around one third of the total French metropolitan population) 


\section{Appendix C}

\section{Table 12: Random parameters logit models for the seven experimental groups}

\begin{tabular}{|c|c|c|c|c|c|c|c|c|}
\hline & \multicolumn{2}{|l|}{ Control } & \multicolumn{2}{|l|}{$\mathrm{CO} 2$} & \multicolumn{2}{|l|}{$\mathrm{CO} 2+\mathrm{IN}$} & \multicolumn{2}{|c|}{$\mathrm{CO} 2+\mathrm{IN}+\mathrm{DN}$} \\
\hline & coef. & $t$ & coef. & $t$ & coef. & $t$ & coef. & $\mathrm{t}$ \\
\hline Air constant & $16.5091 * * *$ & 15.23 & $11.3524 * * *$ & 10.29 & $12.0152^{* * *}$ & 8.76 & $11.5989 * * *$ & 9.29 \\
\hline Bus constant & $11.2187 * * *$ & 8.28 & $11.4042^{* * *}$ & 6.25 & $12.7341 * * *$ & 6.6 & $11.4095^{* * *}$ & 5.63 \\
\hline Car constant & $14.4644 * * *$ & 12.84 & $10.8775^{* * *}$ & 7.93 & $11.0539 * * *$ & 7.11 & $11.7872^{* * *}$ & 8.41 \\
\hline Train constant & $16.2630 * * *$ & 15.36 & $12.8892 * * *$ & 10.56 & $13.3600 * * *$ & 9.07 & $12.7787 * * *$ & 9.48 \\
\hline Duration air & $-0.53978 * * *$ & -13.4 & $-0.48178 * * *$ & -8.05 & $-0.40996 * * *$ & -7.51 & $-0.38142 * * *$ & -7.25 \\
\hline Price & $-0.01383 * * *$ & -14.59 & $-0.00943 * * *$ & -9.11 & $-0.00859 * * *$ & -9.71 & $-0.00849 * * *$ & -9.75 \\
\hline Duration car & $-0.42551 * * *$ & -7.58 & $-0.44067 * * *$ & -6.01 & $-0.26888 * * *$ & -4.81 & $-0.36217 * * *$ & -6.44 \\
\hline Duration bus & $-0.35204 * * *$ & -3.58 & $-0.65078 * * *$ & -4.06 & $-0.52480 * * *$ & -3.62 & $-0.54961 * * *$ & -3.27 \\
\hline Duration train & $-0.52384 * * *$ & -13.57 & $-0.48268 * * *$ & -9.44 & $-0.42923 * * *$ & -9.24 & $-0.40174 * * *$ & -9.18 \\
\hline Sd\# Air const. & $3.83847^{* * *}$ & 6.6 & $2.87851 * * *$ & 5.02 & $3.73043 * * *$ & 4.21 & $2.48682^{* * *}$ & 3.51 \\
\hline Sd\# Bus const. & $3.26989 * * *$ & 5.3 & $4.21043 * * *$ & 5.22 & $3.78482 * * *$ & 4.58 & $4.20088 * * *$ & 4.82 \\
\hline Sd\# Car const. & $3.47406 * * *$ & 5.95 & $3.55067 * * *$ & 4.01 & $4.98509 * * *$ & 4.65 & $2.65945^{* * *}$ & 4.37 \\
\hline Sd\# Train const. & $3.61785^{* * *}$ & 6.23 & $2.39820 * * *$ & 4.8 & $4.45765 * * *$ & 5.02 & $2.97646^{* * *}$ & 4.63 \\
\hline Log-likelihood & -884.8 & & -526.2 & & -542.2047 & & -544.5 & \\
\hline Pseudo R2 adj. & 0.4251 & & 0.3371 & & 0.3185 & & 0.2774 & \\
\hline $\mathrm{N}$ obs. & 1374 & & 582 & & 558 & & 582 & \\
\hline $\mathrm{N}$ respondents & 229 & & 97 & & 93 & & 97 & \\
\hline
\end{tabular}

\begin{tabular}{|c|c|c|c|c|c|c|}
\hline & \multicolumn{2}{|c|}{$\mathrm{CO} 2+\mathrm{IN}+\operatorname{tax}$} & \multicolumn{2}{|c|}{$\mathrm{CO} 2+\mathrm{IN}+\mathrm{BM}$} & \multicolumn{2}{|c|}{$\mathrm{CO} 2+\mathrm{IN}+$ quotas } \\
\hline Air constant & $10.7643^{* * *}$ & 8.03 & $11.3817^{* * *}$ & 10.01 & $8.01959 * * *$ & 9.44 \\
\hline Bus constant & $7.42902 * * *$ & 4.03 & $9.60787 * * *$ & 5.4 & $6.15646 * * *$ & 3.97 \\
\hline Car constant & $12.0906 * * *$ & 8.07 & $11.7217^{* * *}$ & 9.05 & $6.76451 * * *$ & 6.22 \\
\hline Train constant & $11.0296 * * *$ & 7.51 & $12.6830 * * *$ & 10.75 & $8.69681 * * *$ & 10.49 \\
\hline Duration air & $-0.17139 * * *$ & -3.36 & $-0.28053 * * *$ & -5.56 & $-0.24736 * * *$ & -4.45 \\
\hline Price & $-0.00843 * * *$ & -9.01 & $-0.00917 * * *$ & -10.91 & $-0.00802 * * *$ & -9.71 \\
\hline Duration car & $-0.30583 * * *$ & -5.77 & $-0.26346 * * *$ & -5.07 & -0.08254 & -1.54 \\
\hline Duration bus & $-0.13610 *$ & -1.81 & $-0.30333 * * *$ & -3.31 & $-0.22008 * * *$ & -2.58 \\
\hline Duration train & $-0.25880 * * *$ & -6.49 & $-0.31978 * * *$ & -8.53 & $-0.19928 * * *$ & -6.29 \\
\hline Sd\# Air const. & $3.72000 * * *$ & 4.53 & $3.10364 * * *$ & 4.78 & $3.16242^{* * *}$ & 5.25 \\
\hline Sd\# Bus const. & $3.43406 * * *$ & 3.55 & $3.04070 * * *$ & 4.04 & $3.41007 * * *$ & 4.73 \\
\hline Sd\# Car const. & $4.06571 * * *$ & 3.53 & $2.37024 * * *$ & 4.21 & $2.41271 * * *$ & 4.56 \\
\hline Sd\# Train const. & $4.17369 * * *$ & 4.69 & $3.12177^{* * *}$ & 5.77 & $2.52080 * * *$ & 4.8 \\
\hline Log-likelihood & -546.9 & & -496.6 & & -498.9 & \\
\hline Pseudo R2 adj. & 0.2796 & & 0.3174 & & 0.3002 & \\
\hline N obs. & 564 & & 564 & & 510 & \\
\hline $\mathrm{N}$ respondents & 94 & & 94 & & 85 & \\
\hline
\end{tabular}

